\title{
Natural Chimeras of Existing Drugs for Alzheimer's Disease: Expanding the Target Landscape
}

\author{
Illham Dhala, Tabassum Khan, Arati Prabhu* \\ Department of Pharmaceutical Chemistry and Quality Assurance, SVKM's Dr. Bhanuben Nanavati College of Pharmacy, \\ Mumbai, Maharashtra, INDIA.
}

\begin{abstract}
Alzheimer's disease (AD) has emerged as a complex, multi-faceted, neurodegenerative disorder. Multiple mechanisms seem to play a part in its pathogenesis, including amyloid beta aggregation, cholinergic deficit, oxidative stress and neuroinflammation. The current FDA-approved anticholinesterase drugs addressing a single mechanism have turned out to be palliative rather than curative. A number of natural medicinal bioactive are known, which have the potential to overcome many of the unaddressed causal mechanisms contributing to AD. They act as excellent antioxidants, metal chelators, anti-inflammatory mediators and are neuroprotectives. Natural products also have the inherent capability of overcoming some of the adverse effects caused by the currently available drugs. Several researchers have worked on the development of chimeric compounds for AD, in which known cholinesterase inhibitors are linked with natural bioactive components. The resulting novel molecular entities formed have been shown to simultaneously modulate multiple targets with higher efficacy and better safety profiles, demonstrated in experimental models. This review presents a compilation and rational analysis of several natural chimeras of known anti-AD drugs, explored to expand the efficacy and safety profile of current FDA-approved anti-Alzheimer's medications.
\end{abstract}

Key words: Alzheimer disease, Natural bioactives, Cholinesterase inhibitors, Antioxidants, Chimeric compounds, Hepatotoxic.

\section{INTRODUCTION}

Alzheimer's disease (AD) is a chronic, progressive neurodegenerative disorder which is characterized by an increase in the formation of beta amyloid rich senile plaques and neurofibrillary tangles in the brain. ${ }^{1,2}$ The symptoms of AD include progressive memory loss, cognitive decline, psychiatric and behavioral abnormalities and depression. ${ }^{3}$ According to the Established populations for Epidemiological study approximately $4,91,000$ people of age 65 or older will develop Alzheimer's dementia in the United States in 2020. ${ }^{4}$ The average annual incidence in new cases of $\mathrm{AD}$ was found to have a rise of about $0.4 \%$ in the age group of $65-74$ years, $3.2 \%$ in the age $75-84$ years and $7.6 \%$ in the "oldest-old" age group of 85 years and above. Due to the increasing population in the age group of 65 years and older, particularly the oldest- old, the annual number of new cases of AD and other dementias is projected to double by $2050 .^{4}$

The pathogenesis of $\mathrm{AD}$ includes low levels of acetylcholine (ACh), formation of $\beta$-amyloid plaques, irregularities in tau proteins, oxidative stress and dyshomeostasis of bio metals. ${ }^{5}$ Several hypotheses have been proposed for development of AD. These include the cholinergic hypothesis, amyloid hypothesis, tau hypothesis, metal ion hypothesis and excitotoxic hypothesis.

According to the cholinergic hypothesis, the cognitive and memory decline in $\mathrm{AD}$ is because of the reduction in choline levels, mainly acetylcholine in the brain..$^{6-9}$ Protagonists of this hypothesis have successfully developed cholinesterase inhibitors as a means of increasing the levels of acetylcholine in the brain.
Submission Date: 09-08-2020; Revision Date: 05-11-2020; Accepted Date: 08-02-2021

DOI: 10.5530/ijper.55.1s.35 Correspondence: Dr. Arati Prabhu SVKM's Dr. Bhanuben Nanavati College of Pharmacy, Mithibai College Campus, Vile Parle West, Mumbai-400056, Maharashtra, INDIA. Phone no: +919820890221 Email id: arati.prabhu@bncp. ac.in

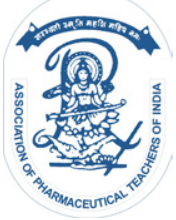

www.ijper.org 
The amyloid theory suggests that an enhanced production of $\beta$-amyloid peptide and its accumulation in the brain leads to neuronal cell death, which causes the $A \beta$ soluble oligomers to form $A \beta$ aggregates which further results in the formation of fibrils which is harmful to the neurons. ${ }^{6}$

The tau hypothesis indicates oxidative stress as a significant contributing factor in AD. Tau is a microtubule-associated scaffolding protein found in axons. Under pathological conditions, there is an increase of tau hyper phosphorylation which renders the protein aggregation-prone, leading to formation of neurofibrillary tangles and neurodegeneration. Oxidative stress is one of the significant factors causing tau aggregation leading to initiation of aggregation of $\beta$-amyloid via tau protein hyper phosphorylation. Therefore, several antioxidants that specifically scavenge oxygen radicals have been found to mitigate $\mathrm{AD}$ and prevent disease progression. ${ }^{10-13}$

The metal ion theory indicates that metals, mainly iron, copper and zinc are involved in the pathogenesis of AD. ${ }^{6,14}$ It has been found that these metal ions slowly accumulate in $\mathrm{AD}$ patients during progression of the disease..$^{15}$ The abnormal accumulation of metals in the brains of $\mathrm{AD}$ patients is closely linked to the development of $A \beta$ plaques and neurofibrillary tangles (NFT), which are the hallmarks of this disease. ${ }^{16}$ The abnormally high concentrations of $\mathrm{Cu}$ and $\mathrm{Fe}$ in the brain catalyze the production of reactive oxygen species (ROS) resulting in additional oxidative stress contributing to $\mathrm{AD}$ pathogenesis. ${ }^{17,18}$ Therefore, reducing metal concentration in the brain by chelating them is another appropriate therapeutic strategy in the management of AD. ${ }^{6}$

Glutamate is the principal excitatory neurotransmitter present in the hippocampus and cortex regions of the brai. ${ }^{19}$ It mostly binds to the ionotropic receptors known as N-methyl D-aspartate (NMDA) receptors and cause modulation in calcium and sodium influx into neuronal cells. ${ }^{19}$ In normal physiological conditions, glutamate binds to the NMDA receptors and depolarization occurs, followed by magnesium ions mediated closing of the cationic channel to prevent the entry of calcium ions in resting stage. ${ }^{19} \mathrm{In} \mathrm{AD}$, there is excessive activation of NMDA type glutamate receptor in neuronal cells that causes the release of bound magnesium ions and allows the entry of calcium ions in the neuronal cells. The excessive influx of calcium ions hampers the neuronal transmission and damages nerve cells, resulting in neurodegeneration, neuritic injury and cell death. ${ }^{19}$

Currently there are five FDA approved drugs for the treatment of $\mathrm{AD}$, of which Tacrine, ${ }^{20}$
Donepezil, ${ }^{21}$ Rivastigmine $^{22}$ and Galantamine ${ }^{23}$ are acetylcholinesterase inhibitors and Memantine ${ }^{24}$ is the only approved non-cholinergic NMDA receptor antagonist drug (Figure 1). Tacrine was the first and most potent acetylcholinesterase (AChE) inhibitor approved by the FDA in 1993 but it is rarely used now due to associated hepatotoxicity. ${ }^{20}$

There is an obvious need for the development of multi-target directed ligands for a holistic and more effective treatment of AD. A lot of anti-Alzheimer research is currently being focused on development of multifunctional chimeras that can address all the hypotheses of $\mathrm{AD}$ development.

One of the domains which offer invaluable resources to complement the existing single-target anti-Alzheimer drugs is the plant kingdom. Several plant bioactive compounds are known which exhibit a range of functional activities that suggest they could play a remarkable role in overcoming all the causative factors contributing to $\mathrm{AD}$.

Acetylcholinesterase inhibitors like Donepezil, Rivastigmine and Tacrine have been fused or molecularly hybridized with natural bioactive by researchers to form novel compounds with multifunctional activities like antioxidant, anti-inflammatory and metal chelation. These chimeric molecules have been found to modulate an expanded $\mathrm{AD}$ target landscape and consequently have an enhanced efficacy profile in comparison to the currently available medications. In this review, we discuss and evaluate the potential of natural chimeras which have been designed by using the hybridization approach using FDA-approved anti-Alzheimer drugs along with other bioactive functional moieties which address the multi-target pathogenesis of AD.

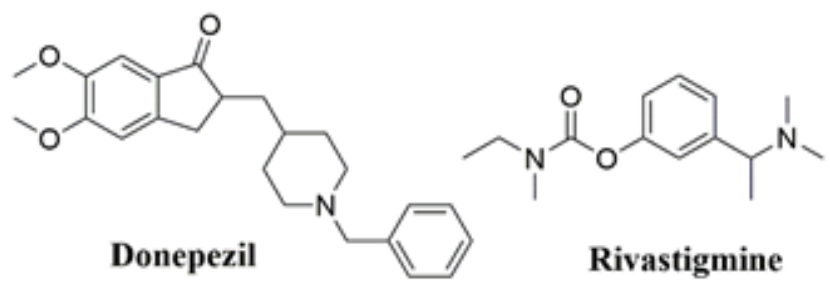

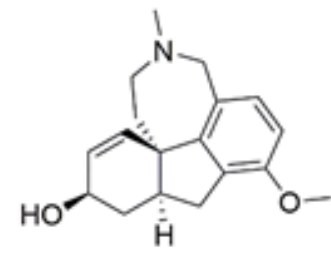

Galantamine

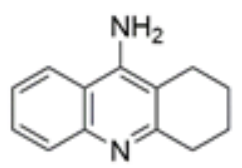

Tacrine
Figure 1: Structures of FDA-approved AChE inhibitor. 


\section{MULTI-TARGET DIRECTED LIGANDS (MTDL)}

The MTDL design strategy is an approach where a single molecule is designed by incorporating multifunctional ligands that can recognize various targets involved in the disease pathology. ${ }^{10}$ Such hybrid compounds which are engineered to simultaneously target various pathways would prove to be more effective in the treatment of AD. ${ }^{25,26}$

Hybrid molecules are entities comprising of two or more structural motifs with distinct pharmacological and biological functions covalently bound within a single molecule. ${ }^{27,28}$ The molecular assembly of hybrid molecules consists of more than one pharmacophore, extracted from different bioactive compounds having different mechanisms of action. They retain the ability to interact simultaneously with multiple molecular targets, thereby producing a range of diverse pharmacological responses that would promote multi-factor disease management. Such compounds also have the potential of reducing the risk of drug-drug interactions and simplify pharmacodynamic and pharmacokinetic aspects of drug administration. ${ }^{11,29}$

\section{NATURAL BIOACTIVE COMPOUNDS}

Nature is a vast treasure trove of powerful antioxidants and free radical scavengers. A large number of antioxidants are naturally found in many plant sources. These primarily belong to the classes of phenolic acids, flavonoids and vitamins.

Plant phenolics are important human dietary components. Phenolic acids such as Ferulic acid and Caffeic acid are known to exhibit excellent antioxidant activities in addition to bestowing other health benefits. Ferulic acid is also a structural fragment of the wonder drug Curcumin, which itself is a well-established antioxidant and anti-inflammatory agent.

Flavonoids, the largest class of naturally occurring polyphenols, including phytochemicals like Apigenin, Genistein and Scutellarin are known for their diverse biological activities, including antioxidant, freeradical scavenger activity as well as anti-inflammatory, neuroprotective, cardioprotective and hepatoprotective effects. $^{30-33}$

Several vitamins and food nutrients, like carotenoids and Vitamins $\mathrm{C}$ as well as Vitamin $\mathrm{E}$ and its water-soluble analogues like Trolox are well-known antioxidants. ${ }^{30}$ The results of the ORAC assay, which measures the antioxidant potential of a compound are commonly referred to as Trolox equivalents as calculated from comparison to a Trolox calibration curve.
However, natural compounds lack AChE inhibitory activity and have several drawbacks like low bioavailability, weak absorption, poor solubility and poor $\mathrm{BBB}$ transport which restricts their use as an anti-AD drug. ${ }^{34}$

\section{CHIMERIC CONJUGATES}

Several chimeric conjugate series have been developed from natural bioactive constituents, using FDAapproved drugs as starting points. These chimeras of Acetylcholinesterase inhibitors like Donepezil, Rivastigmine or Tacrine and their natural bioactive partners exhibit an expanded efficacy profile and have reduced toxicity.

\section{DONEPEZIL CHIMERAS FOR AD}

Donepezil, is a potent, selective, reversible $\mathrm{AChE}$ inhibitor which enhances cholinergic activities by increasing ACh levels in the CNS. ${ }^{35}$ The clinical data of this single- target drug has shown modest and transient outcomes in treatment of moderate and severe AD patients. $^{35,36}$ Donepezil was first approved by the FDA in 1996 and its extended-release form was approved in combination with Memantine in 2014. Although Donepezil is effective in managing the symptoms of AD associated dementia, it does not alter the progression of $\mathrm{AD} \cdot{ }^{37} \mathrm{~A}$ lot of effort has been therefore concentrated on designing new multifunctional agents for AD therapy based on rational modification of the Donepezil scaffold. ${ }^{38}$

Donepezil consists of benzyl piperidine and substituted indanone fragments linked via a methylene bridge (Figure 2). The crystal structure of recombinant human acetylcholinesterase in complex with Donepezil is available in the Protein Data Bank (PDB id 4EY7) which has enabled mapping of its binding interactions. The benzyl piperidine fragment is observed interacting with the AChE catalytic site and has been shown to be the crucial pharmacophoric subunit of the molecule. ${ }^{39}$ The indanone moiety on the other hand, improves the fit of the molecule within the binding site and binds to the peripheral anionic site of $\mathrm{AChE}$ via aromatic stacking interactions. It has been postulated to play a crucial role in inhibiting $A \beta$ aggregation. ${ }^{39}$ In order to introduce antioxidant, anti-inflammatory, metal chelating effects into this molecule, the N-benzyl piperidine (pharmacophore subunit) (Figure 2) has been fused with different bioactive fragments, ${ }^{40}$ Various functionalities on the benzene ring have also been explored in an attempt to increase the inhibition of AChE. ${ }^{40,41}$ 
Table 1 summarizes four series of Donepezil-natural compound chimeras viæ. Feruloyl-Donepezil hybrids, Donepezil-Genistein hybrids, Donepezil-Melatonin hybrids and Donepezil-Trolox hybrids which have shown promising effects on the multiple targets of AD. ${ }^{34,40-42}$ Structure-activity relationships have been developed for cholinesterase inhibition, antioxidant, anti-inflammatory, metal chelation, neuroprotective and $A \beta_{1-42}$ amyloid anti-aggregation activities for each of the series.

\section{Donepezil -Ferulic acid chimeras}

Ferulic acid, a potent antioxidant and anti-inflammatory agent is a hydroxy cinnamic acid analogue with structural similarity to curcumin. It is an abundant phenolic phytochemical found in plant cell walls. It derives its name from Ferulac ommunis or the giant fennel. Ferulic acid is found in high concentrations in bamboo shoots, ${ }^{43,44}$ wheat ${ }^{45}$ flaxseed ${ }^{46}$ and barley grain. ${ }^{47}$

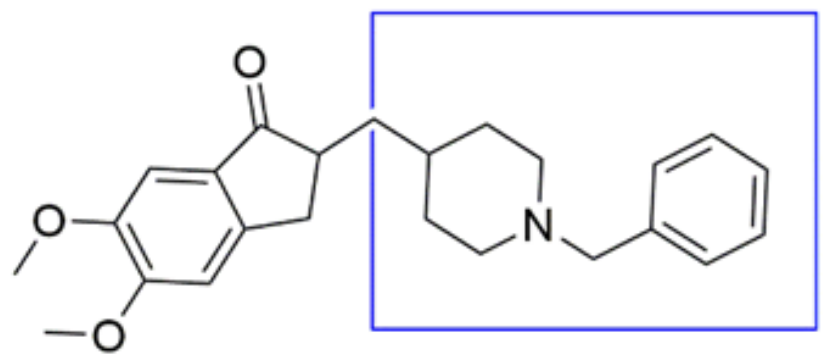

Figure 2: Donepezil with its pharmacophoric unit (boxed).

\begin{tabular}{|c|c|c|c|}
\hline \multicolumn{4}{|c|}{ Table 1: Donepezil chimeric series and their } \\
activities.
\end{tabular}

Like many natural phenols, Ferulic acid shows in vitro antioxidant activity and is reactive towards free radicals such as reactive oxygen species. Studies report that it is capable of reverting the formation of amyloid plaques, reduces oxidative stress and has excellent bio-metal chelating ability. ${ }^{40}$

Feruloyl-Donepezil chimeras were created by fusing the benzyl piperidine methyl fragment of Donepezil with Ferulic acid via an ester linkage. Various substitutions on the benzyl fragment were explored.

\section{AChE inhibition}

The hybrid molecules were screened for AChE inhibition at a fixed concentration of $30 \mu \mathrm{M} .{ }^{40}$ The SAR studies of the hybrid molecules showed that substitution on the aromatic ring of the N-benzyl piperidine subunit leads to a reduction in the AChE inhibitory activity. ${ }^{40}$ Unsubstituted compound 1a (Figure 3) was the most potent AChE inhibitor whereas nitro and bromo substituted compounds designated as $1 \mathrm{~b}$ and $1 \mathrm{c}$ (Figure 3) respectively showed moderate inhibition of AChE. The benzyl piperidine fragment is necessary for interaction with the catalytic site of AChE. Presence of substituents on the benzene ring may negatively impact the binding due to steric hindrance. The crystal structure of Donepezil bound to AChE (PDB id 4EY7) shows that the benzene ring of Donepezil is involved in $\pi-\pi$ stacking with Trp84. Electron-withdrawing substituents like nitro and halogens which diminish the electron density in the $\pi$-cloud of the substituted ring may decrease the electrostatic repulsion with the $\pi$-system of the interacting ring of $\operatorname{Trp} 84$, thereby enhancing the $\pi$-stacking interaction. ${ }^{39,40}$ This may offset the negative effects of steric hindrance and may bestow moderate activity to the nitro and halo-substituted analogues.

Studies reveal that the presence of hydroxyl and methoxy groups on the phenyl propanoid subunit at the other end of the molecules, as was observed in most of the Ferulic acid derivatives leads to retention of

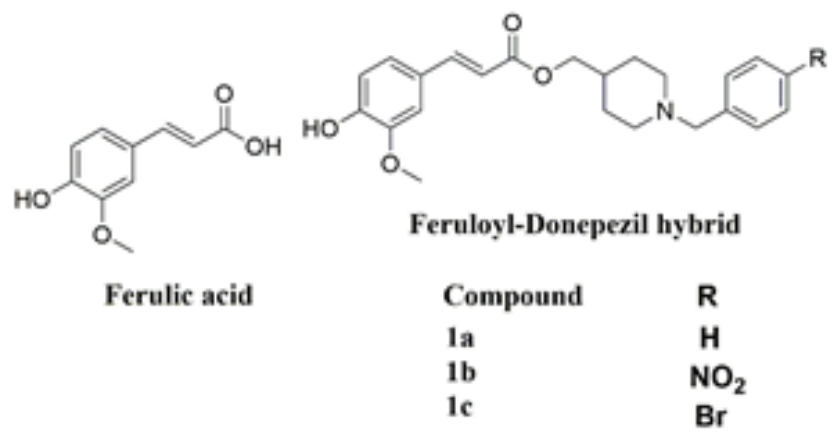

Figure 3: Left- Ferulic acid, Right-Donepezil-Ferulic acid chimeras. 
AChE inhibitory activity. ${ }^{48}$ The importance of methoxy substituents has been also confirmed in other studies where coumarin alkylamines matching the structural attributes of Donepezil were designed and developed as AChE inhibitors.

The conjugated aromatic ring system of Ferulic acid may be capable of mimicking the aromatic stacking interactions of the indanone ring system of Donepezil, which may justify the retention of AChE inhibitory activities of the Donepezil-Ferulic acid hybrids.

\section{Antioxidant activity}

Oxidative stress plays an important role in inducing and activating multiple cell signaling pathways that result in the formation of toxic substances which further promotes the development of $\mathrm{AD}^{40,49}$ Therefore, the designed hybrid series were evaluated for their antioxidant activity by using several in-vitro antioxidant methods ${ }^{40}$ such as the DPPH assay and the ORAC assay DPPH (1, 1-diphenyl-2-picrylhydrazyl ( $\alpha, \alpha$-diphenyl$\beta$-picrylhydrazyl) is a stable organic nitrogen radical and has a deep purple color. ${ }^{50,51}$ The reducing ability of antioxidants towards DPPH is based on the ability of the antioxidant to donate a hydrogen atom to the DPPH radical to form the corresponding colorless hydrazine's while itself getting converted into a radical state. The antioxidant potential is evaluated by electron spin resonance or by monitoring the decrease in absorbance at maximum wavelength at around 520nm. ${ }^{49-54}$

Donepezil-Feruloyl chimeras were screened for their antioxidant activity using DPPH radical scavenging assay at concentrations ranging from 12.5 to $100 \mu \mathrm{M} .{ }^{40}$ Ferulic acid, Isoferulic acid and Trolox were used as standards. ${ }^{40}$ Not surprisingly, all Ferulic acid derived hybrids were found to be powerful antioxidant agents and were effective in scavenging free radicals. ${ }^{40}$ Based on SAR studies, it was inferred that that the para hydroxy group in Ferulic acid is able to donate a positive charge and therefore leads to radical stabilization. This drives their high ROS scavenging activity. In the meta position, the oxygen atom of the hydroxy group is unable to share the charge and hence the radical scavenging activity is adversely affected. ${ }^{40}$ Unsubstituted and nitro substituted compounds i.e. $1 \mathrm{a}$ and $1 \mathrm{~b}$ respectively (Figure 3) counteracted intracellular ROS formation induced by hydrogen peroxide in SH-SY5Y cells in a concentrationdependent manner with a significant decrease of ROS formation at 10, 20 and $40 \mu \mathrm{M}$ whereas bromine substituted compound i.e. 1c (Figure 3) significantly inhibited ROS formation only at $10 \mu \mathrm{M}$, while showing pro-oxidant effects at higher concentrations. ${ }^{40}$

\section{Anti-inflammatory activity}

Suppression of the neuroinflammation process may be a plausible therapeutic intervention for AD. Hybrid compounds were tested by researchers for their in-vivo anti-inflammatory activities. ${ }^{55-57}$ LPS-induced peritonitis tests were carried out on the Donepezil-Feruloyl hybrids. It was found that the unsubstituted and bromine substituted compound i.e. $1 \mathrm{a}$ and $1 \mathrm{c}$ respectively (Figure 3) significantly inhibited leukocyte migration in contrast to the control group (vehicle-DMSO+LPS) and Dexamethasone, exhibiting higher anti-inflammatory activity in leukocyte migration test. ${ }^{40,58-60}$

Compounds 1a and 1c (Figure 3) were able to decrease licking duration during the inflammatory process in the formalin-induced anti-nociceptive study, suggesting an anti-inflammatory activity which may be attributed to the indirect inhibition of inflammatory mediator production or the blockage of their receptors directly. ${ }^{61,62}$ These compounds did not improve the motor activity in mice models. ${ }^{63}$

\section{Metal chelation}

A significant amount of literature proof states that bio metal dyshomeostasis of metal ions such as $\mathrm{Cu}^{2+}, \mathrm{Zn}^{2+}$, $\mathrm{Fe}^{2+}$ and $\mathrm{Fe}^{3+}$ in $\mathrm{CNS}$ and their interactions with the precursor of amyloid protein (APP) and $A \beta$ precursors lead to AD pathology. ${ }^{16,64,65}$ Copper and iron, are usually redox active and are able to generate ROS through the Fenton and Haber-Weiss reaction and facilitate the formation of neurotoxic $A \beta$ oligomers. Metal chelating compounds may serve as an important therapeutic approach in treating $\mathrm{AD} .{ }^{39}$

Donepezil-Feruloyl chimeras, either unsubstituted or substituted with nitro and bromine groups (1a, 1b, 1c, Figure 3) were found to selectively chelate bio metals such as $\mathrm{Cu}^{2+}, \mathrm{Fe}^{2+}$, but not $\mathrm{Fe}^{3+}$ or $\mathrm{Zn}^{2+}$. The shift in absorption spectra after incubation of the compound solutions with metal salts were monitored using UV-Visible spectroscopy at $200-400 \mathrm{~nm} .^{40,66}$

\section{Neuroprotective and $A \beta_{1-42}$ anti-aggregation activities}

Among different forms of $A \beta$ aggregates, soluble $A \beta$ oligomers $(\mathrm{A} \beta \mathrm{O})$ cause selective synaptic dysfunction and neuronal loss in the cortex and in the hippocampal regions of the brain. ${ }^{67-70}$ Among the Donepezil-Feruloyl hybrids, the unsubstituted compound 1a (Figure 3) was found to counteract ROS formation and neuronal death induced by $A \beta_{1-42}$ oligomers in neuronal SH-SY5Y cells. ${ }^{40,70}$ 


\section{Donepezil-Genistein hybrids}

Genistein (4,5,7-trihydroxyisoflavone) found abundantly in soybeans and red clover containing plants like Trifolium pratense, is known to possess a wide spectrum of biological effects such as antioxidant and metal chelation as well as neuroprotective effects against $A \beta{ }^{71-75}$ It also shows anti-inflammatory activity which has potential in delaying the progression of a neurodegenerative disease like AD.

In an attempt to supplement this activity profile with AChE inhibition, researchers ${ }^{34}$ developed a series of Donepezil-Genistein hybrid molecules and evaluated their potential for AChE inhibition, antioxidant, metal chelation, inhibitory effects on $A \beta$ aggregation and neuroprotective effects in the mouse scopolamine model of memory impairment. ${ }^{34}$

The piperidine ring of the pharmacophoric benzyl piperidine motif of Donepezil was replaced with various lipophilic ring-opened tertiary amines. Hydroxy groups at 4' and 7 positions of Genistein were coupled with various alkyl benzylamines on either side $(2 \mathrm{a}, 2 \mathrm{~b})$ as well as simultaneously on both terminal sides (2c).

\section{AChE inhibition}

While all modifications gave compounds, which exhibited good inhibition against AChE, the longer, more lipophilic amine $2 \mathrm{c}$ showed the highest potency. On the basis of inhibition kinetic analysis and molecular modeling studies, the authors reported that compound $2 \mathrm{c}$ showed a mixed-type inhibition, binding to both CAS and PAS of AChE, thereby inducing a strong inhibitory effect. ${ }^{34}$

\section{Antioxidant activity}

The ORAC assay method measures the antioxidant scavenging activity against the peroxyl radical, induced by 2, 2'-azobis-(2-amidino-propane) dihydrochloride $(\mathrm{AAPH})$, at $37^{\circ} \mathrm{C}$. The peroxyl radical reacts with a fluorescent probe, usually fluorescein or peroxyl radical, induced by reduction in fluorescence that can be evaluated using spectrofluorimetry. ${ }^{52-54,76}$ Trolox is used as a reference standard, fluorescein is used as the fluorescent probe $e^{77-79}$ and the specified ORAC values of the tested potential antioxidants are stated as Trolox equivalents. ORAC assay measures hydrogen atom donating ability of antioxidants. Higher ORAC values indicate good antioxidant capacity. Another assay which has been used to determine Trolox equivalents is the TEAC (Trolox equivalent antioxidant capacity) assay, which is based on scavenging of 2, 20 -azinobis-(3- ethyl benzothiazoline-6- sulfonate) radical anions (ABTS-). ${ }^{52}$
ORAC assay used to determine antioxidant potential of Donepezil-Genistein chimeras ${ }^{34}$ showed that compounds where at least one of the Genistein hydroxy groups were left exposed (2a, 2b, Figure 4) had higher antioxidant activity than compound $2 \mathrm{c}$ where both the 4' and 7 hydroxy groups were substituted with the lipophilic alkyl benzyl amines. This further reiterates the importance of free hydroxy groups for good radical scavenging and antioxidant ability.

\section{Metal chelation}

The chelating ability of Donepezil-Genistein hybrids, 2a, 2b and 2c (Figure 4) for the biologically relevant metal ions $\mathrm{Cu}^{2+}, \mathrm{Fe}^{2+}, \mathrm{Zn}^{2+}$ and $\mathrm{Al}^{3+}$, was studied by researchers ${ }^{34}$ and found positive for $\mathrm{Cu}^{2}$ and $\mathrm{Al}^{3+}$ but not for $\mathrm{Fe}^{2+}$ and $\mathrm{Zn}^{2+}$.

Neuroprotective and $A \beta_{1-42}$ anti-aggregation activities

The Donepezil-Genistein hybrids $2 \mathrm{a}, 2 \mathrm{~b}$ and $2 \mathrm{c}$ (Figure 4) exhibited moderate inhibition of self-induced $A \beta$ aggregation, but higher $\mathrm{Cu}^{2+}$-induced $\mathrm{A} \beta$ aggregation inhibitory activity in comparison to curcumin. ${ }^{34}$ Compound 2c showed significant inhibition of $A \beta$ aggregation, induced disaggregation of $A \beta$ fibrils generated by $\mathrm{Cu}^{2+}$ - induced $\mathrm{Ab}$ aggregation and reversed cognitive deficit. ${ }^{34}$

\section{Donepezil-Melatonin hybrids}

Melatonin, an endogenous neurohormone, has been shown to have a profound effect on the pathogenesis of $\mathrm{AD}$, addressing many of the associated causative factors. It is a powerful antioxidant and free radical scavenger, ${ }^{80-83}$ efficiently attenuates hyper phosphorylation of tau ${ }^{84-89}$ modulates the synthesis and maturation of amyloid precursor protein (APP) (41) butyrylcholinesterase (eqBuChE and $\mathrm{hBuChE}$ and also
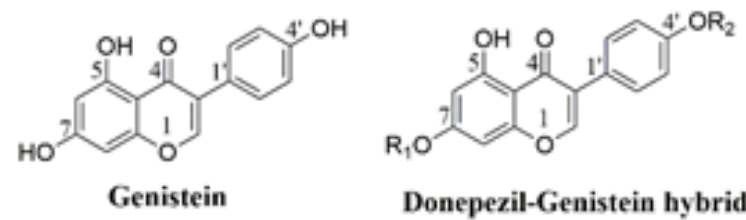

Donepezil-Genistein hybrids

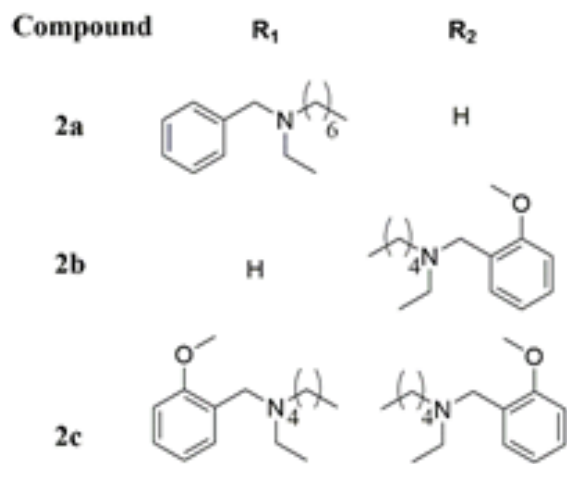

Figure 4: Left- Genistein, Right-Donepezil-Genistein chimeras. 
inhibits the progressive formation of $\beta$-sheet and/or amyloid fibrils..$^{90-92}$

Much of the antioxidant effectiveness of Melatonin in vivo has been attributed to the cascade of Melatonin antioxidant metabolites produced (Figure 5). In presence of ROS, Melatonin sequentially forms the melatonin radical cation and melatoninyl neutral radical which undergoes rearrangement to cyclic 3-hydroxy melatonin, $\mathrm{N}(1)$-acetyl-N(2)-formyl-5-methoxykynuramine) (AFMK), N(1)-acetyl-5-methoxykynuramine (AMK) as well as 6-hydroxy melatonin via one electron transfer processes. ${ }^{93}$

Each of these products of rearrangement also have potent antioxidant activities.

\section{AChE inhibition}

Donepezil-Melatonin hybrids were designed and synthesized ${ }^{41}$ and were shown to possess AChE inhibitory activities when measured by a spectrophotometric enzyme-based assay method. ${ }^{94}$

Compounds $3 \mathrm{a}$ and $3 \mathrm{~b}$ (Figure 6 ) which are direct hybrids of Melatonin and the benzyl piperidine moiety of Donepezil showed less AChE inhibition than Donepezil but similar antioxidant activity to Melatonin. Compound $3 c$ (Figure 6) on the other hand, where the amide bond is attached in reverse order showed good AChE inhibition comparable to Donepezil after optimization of molecule length.

The methoxy indole scaffold of Melatonin possibly acts as an isostere of the methoxy indanone fragment of Donepezil, thereby retaining the hydrophobic and $\pi$-stacking binding interactions of this fragment within the acetylcholinesterase active site. It is possible that

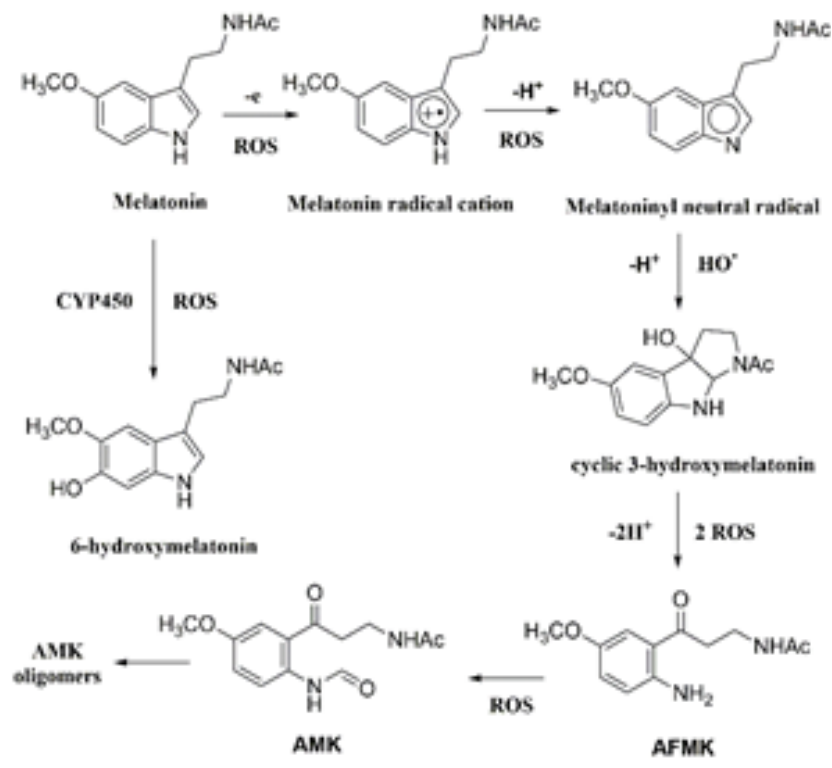

Figure 5: Antioxidant mechanism of action of Melatonin. in the ROS microenvironment as is found in $\mathrm{AD}$, the direct Melatonin hybrids (3a, 3b) undergo a molecular rearrangement similar to Melatonin, resulting in a molecules which have a different shape and relative orientation of the benzyl piperidine and methoxy indole scaffolds, due to which the molecules are unable to optimally bind into the AChE pocket, resulting in only moderate activity. However, incorporating a reverse amide (as in 3c) may inhibit the rearrangement process, thereby retaining a conformation amenable to the AChE pocket resulting in good inhibition. Variation of substituents on the benzene ring of the benzyl piperidine fragment showed that substituents such as methyl group ( $3 \mathrm{~b}$, Figure 6) at ortho position of the benzene ring are more active than those at meta or para position. ${ }^{41}$ Linker length between the piperidine and amide group also plays an important role in AChE activity with a two-carbon linker (3c, Figure 6) showing highest AChE inhibition.

\section{Antioxidant activity}

The antioxidant potential of Donepezil-Melatonin hybrids was determined via the ORAC assay. It was found that compounds with a methyl substituent on the benzene ring (3b, Figure 6 ) and an one or two-carbon methylene ( $3 \mathrm{c}$, Figure 6 ) linker between the amide and the piperidine ring showed the highest protective capability, radical scavenging and antioxidant profile higher than Melatonin and Trolox. ${ }^{41}$

\section{Metal Chelation}

Unsubstituted indole and benzene rings containing Donepezil-melatonin hybrids like compound $3 \mathrm{c}$ (Figure 6) were found to chelate bio metals such as

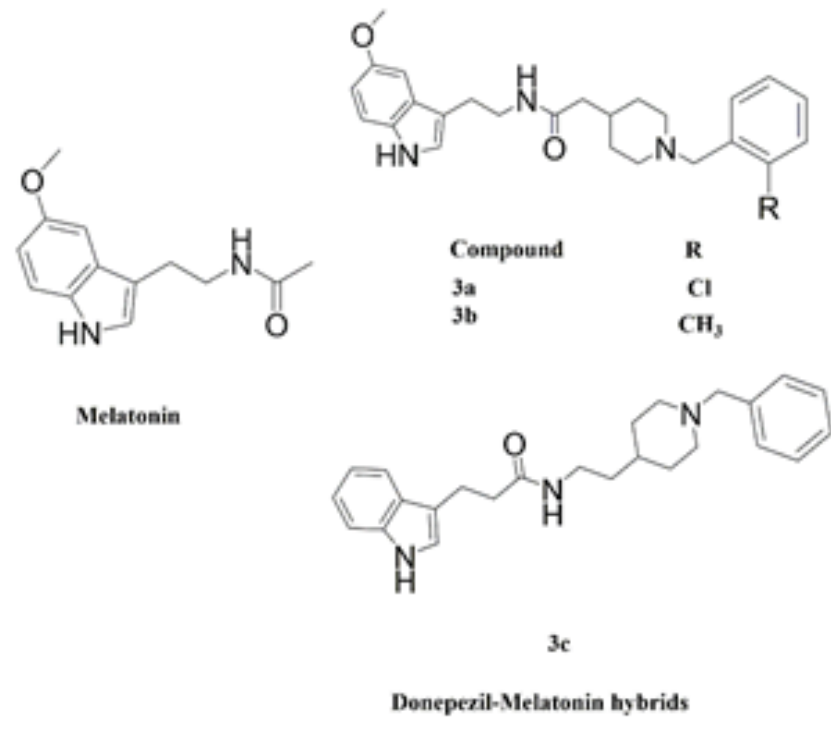

Figure 6: Left- Melatonin, Right- Donepezil-Melatonin chimeras. 
copper, iron and zinc and was evaluated by UV-Vis spectroscopy. ${ }^{41}$

\section{Neuroprotective and $A \beta_{1-42}$ anti-aggregation activities}

The Thioflavin-T fluorimetric assay was carried out on all synthesized hybrids using curcumin and resveratrol as reference compounds. ${ }^{41,95,96}$ It was observed that electron withdrawing groups like chlorine (3a, Figure 6) on the benzene ring were beneficial and bestowed good $A \beta_{1-42}$ self-induced aggregation inhibitory activity. It was also reported that linker length did not influence the inhibition of $A \beta_{1-42}$ self-induced aggregation. ${ }^{41}$

Donepezil-Trolox hybridsTrolox is a watersoluble analogue of Vitamin $\mathrm{E}$ which has strong antioxidant effects, reduces oxidative stress, exhibits neuroprotective effects through ROS scavenging and decreases neurotoxicity caused by $A \beta .{ }^{42}$ DonepezilTrolox hybrids were constructed by joining the Trolox molecule with benzyl piperidine scaffold via an amidepoly-(methylene) linker.

\section{AChE inhibition}

It was found that groups such as fluorine (4a, Figure 7) at ortho position of the benzene ring show excellent AChE inhibition in addition to retention of antioxidant, metal chelation and neuroprotective properties. Linker length was also found to play an important role with two-methylene linker showing higher inhibitory activities. ${ }^{42}$ It is possible that ortho substitution on the benzene ring as well as the correct linker length bestows the optimum bioactive conformation to the molecule and contributes favorably towards AChE inhibition.

\section{Antioxidant activity}

The antioxidant potential of Donepezil-Trolox hybrids was evaluated by carrying out DPPH radical scavenging assay, using Trolox as a reference standard. ${ }^{42,54}$ It was reported that all hybrid compounds retained their antioxidant activities in comparison to the reference standard ${ }^{42}$ indicating that coupling with benzyl piperidine does not adversely affect the antioxidant capabilities of Trolox.

Along with the DPPH radical scavenging assay, the ORAC assay was done on the Donepezil-Trolox hybrids. The researchers reported that compound 4a (Figure 7) in which fluorine is at ortho position exhibits ORAC value greater than 1 , pointing to superior antioxidant activities when compared to Trolox. ${ }^{42}$

\section{Metal chelation}

Fluorine-substituted Donepezil-Trolox hybrids like compound 4a (Figure 7) were found to chelate bio metals such as copper, zinc and iron. ${ }^{35,42}$ Metal chelation for copper was evaluated by UV-Vis spectrometry using HEPES buffer and investigated at an absorption maximum of $246 \mathrm{~nm}$ by determining the isobestic point. ${ }^{42}$

\section{Neuroprotective and $A \beta_{1-42}$ anti-aggregation activities}

The Thioflavin $\mathrm{T}$ (ThT) fluorescence assay was carried out on all Donepezil-Trolox hybrid series using transmission electron microscopy (TEM). ${ }^{42,97}$ It was reported that fluorine substituted compound $4 \mathrm{a}$ (Figure 7) can inhibit $A \beta_{1-42}$ fibril formation and copper induced $A \beta_{1-42}$ aggregation effectively. ${ }^{42}$ Further compound $4 a$, when treated against oxidative injuries on PC12 cells was reported to show poor neuroprotective activity in oligomycin-A assay whereas it showed good neuroprotective activity in hydrogen peroxide and rotenone assays. ${ }^{42,98}$ The neuroprotective effect was also carried out against LPS-stimulated inflammation on $\mathrm{BV}_{-2}$ microglial cells. ${ }^{42,99}$ It was reported that compound 4a showed higher inhibition of NO production in LPSsimulated $\mathrm{BV}_{-2}$ cells than the reference compounds Donepezil and Trolox. Thus, this compound also showed significant anti-neuroinflammatory activities ${ }^{42}$ Inhibiting ROS production can result in suppression of intracellular proinflammatory signals. LPS induces ROS production whereas compound 4 a effectively decreases the intracellular ROS accumulation. ${ }^{42}$ Compound 4 a was reported to be a promising neuroprotective agent based on various assays carried out by researchers. Moreover, this Donepezil-Trolox chimeric compound showed good in vitro blood-brain barrier permeation when tested in the parallel artificial membrane permeation assay for $\mathrm{BBB}$ (PAMPA-BBB), ${ }^{42}$ which is a necessary attribute for potential anti-AD drugs.

All four Donepezil hybrid series (Table 1) have been subjected to pharmacokinetic and pharmacodynamic evaluations viz in-vitro BBB permeation assays, ${ }^{41,42,100}$ cognition and memory improvement tests, ${ }^{42,101,102}$ on specific mouse models and in-vitro toxicity profiling. ${ }^{42}$

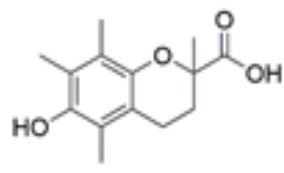

Trolox

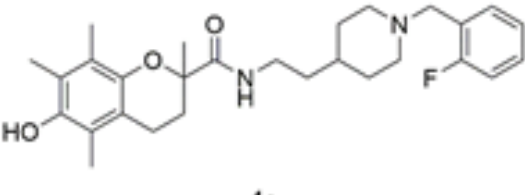

$4 \mathbf{a}$
Figure 7: Left- Trolox, Right- Donepezil-Trolox chimera. 
It has been reported that all the hybrid molecules have a better safety index as well as permeation rate as compared to the parent compounds.

\section{RIVASTIGMINE CHIMERAS FOR AD}

Rivastigmine, is the only FDA approved carbamate AChE inhibitor for the treatment of mild to moderate AD. However, as found in clinical trials, Rivastigmine does not prevent the course of illness but only leads to a modest improvement in cognitive functions. ${ }^{103}$ This can be attributed to the multifactorial nature of $\mathrm{AD}$.

The carbamate moiety is the pharmacophore subunit of Rivastigmine which binds to the AChE catalytic site and is responsible for cholinesterase inhibitory activity.

The mechanism of action of Rivastigmine, as revealed by X-ray crystallography studies has been reported ${ }^{104}$ to involve carbamoylation of an AChE active-site serine residue, with concomitant formation of leaving group S-3-[1-(dimethylamino)-ethyl]-phenol (NAP) (Figure 8). The carbamoyl moiety is covalently linked to the activesite serine S200 which is part of the catalytic triad and remains attached until it is slowly removed by hydrolysis making Rivastigmine a pseudo-irreversible inhibitor of AChE. ${ }^{104}$

Table 2 summarizes three series of hybrid molecules which have shown promising effects on the multiple targets of $\mathrm{AD}^{103,105,106}$ viz. Rivastigmine-hydroxy cinnamic acid hybrids, Rivastigmine-Apigenin hybrids and Rivastigmine-scutellarin hybrids.

Multitarget design ligand strategies have been developed where the AChE inhibiting carbamoyl fragment of Rivastigmine is coupled with various bioactive

\begin{tabular}{|c|c|c|c|}
\hline \multicolumn{4}{|c|}{ Table 2: Rivastigmine chimeric series and their } \\
activities. \\
\hline $\begin{array}{c}\text { Sr. } \\
\text { no. }\end{array}$ & Hybrid series & Activity profile & Ref. \\
\hline 1. & $\begin{array}{c}\text { Rivastigmine- } \\
\text { hydroxy } \\
\text { cinnamic acid } \\
\text { hybrids }\end{array}$ & $\begin{array}{c}\text { Anticholinesterase, } \\
\text { antioxidant, metal chelation, } \\
\text { A } \beta \text { anti-aggregating activity, } \\
\text { neuroprotective action against } \\
\text { A } \beta \text { aggregation }\end{array}$ & 106 \\
\hline 2. & $\begin{array}{c}\text { Rivastigmine- } \\
\text { Apigenin } \\
\text { hybrids } \\
\text { antioxidant, metal chelation, } \\
\text { A } \beta \text { anti-aggregating activity, } \\
\text { neuroprotective action against } \\
\text { A } \beta \text { aggregation }\end{array}$ & 105 \\
\hline 3. & $\begin{array}{c}\text { Anticholinesterase, } \\
\text { Rivastigmine- } \\
\text { scutellarin } \\
\text { hybrids }\end{array}$ & $\begin{array}{c}\text { Antioxidant, metal chelation, } \\
\text { A } \beta \text { anti-aggregating activity, } \\
\text { neuroprotective action against } \\
\text { A } \beta \text { aggregation }\end{array}$ & 103 \\
\hline
\end{tabular}

molecules with favorable properties for treatment of AD functioning where they replace the NAP fragment. These molecules have been explored in order to investigate their potential of possessing an expanded activity profile for a more holistic treatment of AD.

Structure-activity relationships have been developed for cholinesterase inhibition, antioxidant, metal chelation, neuroprotective and $A \beta_{1-42}$ amyloid anti-aggregation activities for each of the series.

\section{RIVASTIGMINE-CAFFEIC ACID HYBRIDS}

Caffeic acid, an analogue of hydroxy cinnamic acid is found in all plants as it is a key intermediate in the biosynthesis of lignin. ${ }^{107}$ It is found in the bark of Eucalyptus globules, ${ }^{108}$ the herb Dipsacus asperoides, ${ }^{109}$ the freshwater fern Salvinia molesta, ${ }^{110}$ the mushroom Phellinus linteus $^{111}$ and in a variety of herbs such as thyme, sage and, spearmint, Ceylon cinnamon and star anise. Caffeic acid decreases ROS generation and $A \beta$ aggregation, effectively blocks the progression of $\mathrm{AD}$ and prevents oxidative damage in neurons. ${ }^{106}$

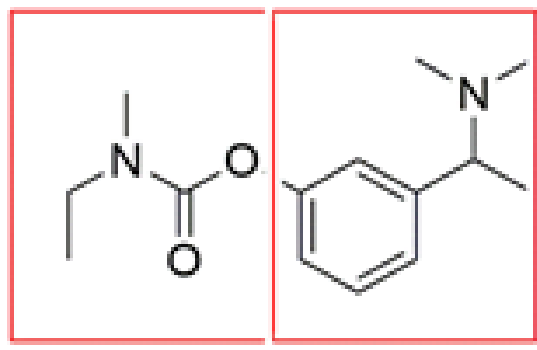

\section{Carbamate NAP}

Figure 8: Subunits of Rivastigmine showing the carbamate (pharmacophoric) and NAP.<smiles>[X]c1ccc(NNC(=O)/C=C/c2ccc(O)c([R20])c2)cc1</smiles><smiles>O=C(O)/C=C/c1ccc(O)c(O)c1</smiles>

Caffeic acid

$\begin{array}{llll}\text { Compound } & \mathrm{R} & \mathrm{n} & \mathrm{X} \\ 5 \mathrm{a} & \mathrm{H} & 0 & \mathrm{O} \\ 5 \mathrm{~b} & \mathrm{OCH} 3 & 0 & \mathrm{O} \\ 5 \mathrm{c} & \mathrm{H} & 1 & \mathrm{O} \\ 5 \mathrm{~d} & \mathrm{OCH} 3 & 1 & \mathrm{O} \\ 5 \mathrm{e} & \mathrm{H} & 2 & \mathrm{O} \\ 5 \mathrm{f} & \mathrm{OCH} 3 & 2 & \mathrm{O} \\ 59 & \mathrm{H} & 0 & \mathrm{~N} \\ 5 \mathrm{~h} & \mathrm{OCH} 3 & 0 & \mathrm{~N}\end{array}$

Rivastigmine-hydroxy cinnamic acid hybrids

Figure 9: Left- Caffeic acid, Right- Rivastigmine-Caffeic acid chimeras. 
Researchers synthesized two types of Rivastigminehydroxy cinnamic acid hybrids - carbamate analogues (5a-5f) and urea analogues (5g, 5h) (Figure 9). Other modifications explored were the ring substituents on the benzene of cinnamic acid (3,4-dihydroxy derivatives caffeic acid analogues; 4-hydroxy, 3-methoxy derivatives - ferulic acid analogues) and the linker length between the amide and the aromatic ring.

\section{AChE inhibition}

All the hybrid compounds $5 \mathrm{a}-5 \mathrm{~h}$ exhibited enhanced cholinesterase inhibition activity for both AChE and $\mathrm{BuChE}$ as compared to the native drug Rivastigmine. ${ }^{106}$ The longer caffeic acid fragments (compared to the NAP fragment) may have the capacity of having additional binding interactions within the AChE pocket which may be responsible for the higher AChE inhibition of the hybrid molecules.

\section{Antioxidant activity}

The DPPH assay was carried out to evaluate the antioxidant potential in Rivastigmine-caffeic acid hybrids. The urea analogues with two hydroxy groups attached to the phenyl ring and carbamate analogues (5g) with a one-carbon spacer and two hydroxy groups attached to the phenyl ring (5c) exhibited the highest radical scavenging activities (Figure 9). ${ }^{106}$

\section{Metal chelation}

Compounds which are capable of chelating metals like copper, zinc and iron and have the ability to cross $\mathrm{BBB}$ would be invaluable in treatment of $\mathrm{AD} .{ }^{112,113}$ Rivastigmine-caffeic acid hybrid with a two-carbon spacer (5e, Figure 9) was found to have copper chelating properties. It also reduced copper-induced $A \beta$ aggregation and oxidative stress. ${ }^{106,114}$ It was surmised by the authors that chelation activity may be due to the presence of the two phenyl hydroxyl groups. ${ }^{106}$

\section{Neuroprotective and $A \beta_{1-42}$ anti-aggregation activities}

Glutamate and hydrogen peroxide assays were carried out in order to evaluate neuroprotective effects of Rivastigmine-caffeic acid hybrids. Urea analogues (5g, $5 \mathrm{~h}$, Figure 9) exerted good neuroprotective effects in glutamate-induced cell death. Hydroxy-substituted caffeic acid hybrids $(5 \mathrm{a}, 5 \mathrm{c}, 5 \mathrm{e}, 5 \mathrm{~g})$ potently inhibited the $A \beta_{1-42}$ self-aggregation whereas the methoxy-substituted ferulic acid hybrids (5b, $5 \mathrm{~d}, 5 \mathrm{f}, 5 \mathrm{~h}$ ) showed moderately potent effects in $A \beta_{1-42}$ self-aggregation. ${ }^{106}$

\section{Rivastigmine-Apigenin hybrids}

Apigenin (4',5,7-trihydroxyisoflavone) is a natural flavone, found abundantly in parsley, celery and chamomile. It has been found to possess antioxidant, neuroprotective, anti-inflammatory and anti-A $\beta$ aggregation activities. ${ }^{105,115}$ When these moieties are coupled with the carbamoyl portion of Rivastigmine which inactivates AChE, multifunctional ligands targeting the major causative factors of $\mathrm{AD}$ are obtained.

\section{AChE inhibition}

A series of Rivastigmine-Apigenin hybrids were developed ${ }^{105}$ and evaluated for $\mathrm{AChE}$ inhibition These studies demonstrated the strategic success of capping the Apigenin terminal hydroxy groups with aliphatic carbamates.Compound 6a (Figure 10) showed a fourfold improvement in $\mathrm{AChE}$ inhibition as compared to Rivastigmine. ${ }^{105}$ The authors attributed this to a significant improvement in the overall binding of the hybrid molecule within the AChE binding cavity. Molecular docking studies of compound 6a within AChE showed it to simultaneously occupy the entire peripheral anionic site, catalytic site and the midgorge sites, with both the carbamate fragment as well as the chromone scaffold of apigenin contributing via favorable hydrogen bonding, $\pi-\pi$ stacking as well as hydrophobic binding interactions.

\section{Antioxidant activity}

The Rivastigmine-Apigenin hybrids were evaluated for antioxidant activity ${ }^{105}$ using the ORAC assay. Apigenin is a natural flavone with three hydroxy groups at 4', 5 and 7 positions. The Rivastigmine-Apigenin hybrids with the 4' and 7 hydroxy groups substituted with carbamate functionalities (eg. Compound 6a, Figure 10) exhibited significantly less antioxidant activity than Apigenin, but were equal in potency to the reference standard Trolox. Substituting all three hydroxy groups drastically lowered the antioxidant activity of the molecules.

\section{Metal chelation}

The 5-hydroxy and 4-ketone groups of RivastigmineApigenin hybrids have the potential of exhibit metalchelating properties. Compound 6a (Figure 10) exhibited

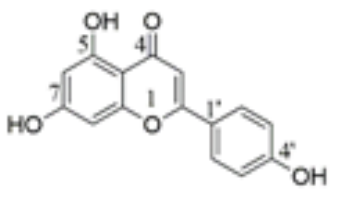

Apigenin
$6 a$

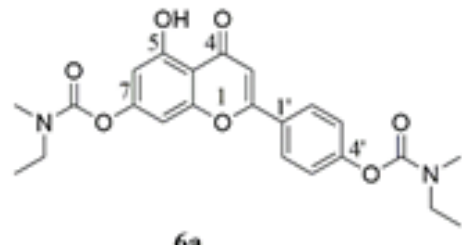

Figure 10: Left- Apigenin, Right- Rivastigmine-Apigenin chimera. 
selective metal chelation for copper and aluminum but not iron and zinc metal ions. ${ }^{105}$

\section{Neuroprotective and $A \beta_{1-42}$ anti-aggregation activities}

The effects on $A \beta$ aggregation were evaluated for the Rivastigmine-Apigenin hybrids ${ }^{105}$ by performing Thioflavin T (ThT) fluorescence assay using curcumin as a reference standard. ${ }^{105}$ Dual carbamates like compound 6a (Figure 10) showed excellent neuroprotective ability as well as inhibition of self-mediated $A \beta_{1-42}$ aggregation, huAChE-induced $\mathrm{A} \beta_{1-40}$ aggregation and $\mathrm{Cu}^{2+}$-mediated $A \beta_{1-42}$ aggregation. However, bulky substituents on the hydroxy group at 5-position on the chromone scaffold fragment lowered the anti-aggregation effects.

\section{Rivastigmine-Scutellarin hybrids}

Scutellarin (4',5,6-trihydroxy flavone-7-glucuronide) is a flavone first isolated from the Chinese herb Erigeron breviscapus. ${ }^{116}$ Its broad spectrum of pharmacological activities include free radical scavenging ability, antiinflammatory efficacy, neuroprotection and ability to inhibit $A \beta$ fibril formation. ${ }^{117-119}$ However, poor solubility, weak oral absorption and poor blood-brain barrier (BBB) penetration has restricted the clinical application of scutellarin. ${ }^{120,121}$ Researchers ${ }^{103}$ synthesized and evaluated a series of Rivastigmine-scutellarin hybrids.

\section{AChE inhibition}

It was reported that substitution on the flavonoid nucleus as well as the carbamate capping groups affect cholinesterase inhibition. Methoxy (7a, 7b, Figure 11) or hydroxy (8a, Figure 11) substituted phenyl rings on the scutellarin fragment show better cholinesterase inhibition as compared to Rivastigmine, with the 5-methoxy substitution on the flavonoid nucleus showing higher activity as compared to 5-hydroxyl substitution. The carbamate nitrogen was completely substituted with small alkyl fragments such as methyl, ethyl and isopropyl groups as well as with rings such as morpholine, piperidine and substituted piperazines. Compounds containing N, N-diethyl carbamate side chain (7b) and N-ethyl-methyl carbamate side chain (7a) exhibited strongest inhibition for $\mathrm{AChE}$ and $\mathrm{BuChE}$ respectively. Hybrid series with carbamate moiety at para position (Figure 11) were also reported to have more potent activity than those at meta position. ${ }^{103}$

\section{Antioxidant activity}

SAR studies on Rivastigmine-scutellarin hybrids using ORAC fluorescein assay ${ }^{97}$ showed that presence of carbamate side chains on to the flavonoid nucleus

decreases the antioxidant potential but they have little influence on the radical scavenging activity on the same nucleus. ${ }^{103}$ Compounds with 5-hydroxyl groups (8a, Figure 11) exhibit better antioxidant properties in comparison to 5-methoxy groups (7c, Figure 11). Compound 8a exhibited best antioxidant activity which is 1.3 -fold higher than the reference standard Trolox. ${ }^{103}$

\section{Metal chelation}

Researchers monitored metal chelation of Rivastigminescutellarin hybrids using UV-visible spectroscopy at 322-341 nm and reported that compounds containing $\mathrm{N}, \mathrm{N}$-diethyl carbamate side chain (7b, Figure 11) showed excellent metal chelation of bio metals such as copper, aluminum but not iron and zinc. ${ }^{103}$ Chelation can be attributed to the 5-hydroxyl and 4-carbonyl groups of the flavonoid nucleus.

\section{Neuroprotective and $A \beta_{1-42}$ anti-aggregation activities}

Studies ${ }^{103}$ evaluating the neuroprotective capacities of Rivastigmine-scutellarin hybrids against oxidative stress showed that compounds with 5-hydroxyl groups exhibit a higher cell survival ratio as compared to compounds with 5-methoxy group substituents, possibly due to the capability of hydroxy group of capturing the free radicals. The $\mathrm{N}, \mathrm{N}$-diethyl carbamate side chain containing compound 8a (Figure 11) exhibited remarkable neuroprotective effects. ${ }^{103}$

\section{SAFE TACRINE CHIMERAS FOR AD}

Tacrine, was the first FDA approved anti-AD drug, which had dual inhibitory properties of acetyl cholinesterase and butyl cholinesterase inhibition, but it was withdrawn from the market shortly after FDA approval due to serious hepatotoxicity. ${ }^{122}$ Due to the good inhibitory activity, low molecular weight and its ability to reduce $A \beta$-induced neurotoxicity, Tacrine has been widely investigated by researchers worldwide, especially for the synthesis of safer multi-target

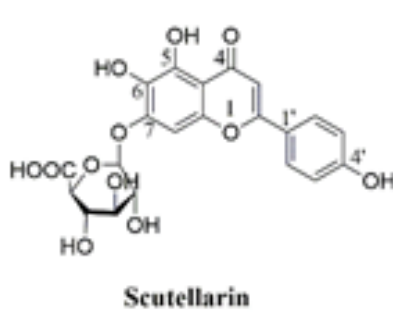

Figure 11: Left- Scutellarin, Right- Rivastigmine-Scutellarin chimeras. 
directed ligands (MTDLs) for AD treatment. ${ }^{123}$ Several assays have been used by researchers to monitor the hepatotoxicity of Tacrine analogues such as the MTT colorimetric assay, ${ }^{124}$ ALT and AST activity assay $\operatorname{method}^{125}$ and the Cell Titre Glow assay. ${ }^{126}$

Tacrine hybrids with several fragments, some of them known hepatoprotectives, have been extensively studied in order to identify safer anti-AD molecules without any hepatotoxicity liability.

Table 3 summarizes four series of hybrid molecules which have shown promising effects on the multiple targets of $\mathrm{AD}^{127-130}$ viz. Tacrine-Silibinin derivatives, Tacrine-Trolox hybrids, Tacrine-Scutellarin compounds and Tacrine-Rhein hybrids.

\section{Tacrine-Silibinin analogues ${ }^{127}$}

Silibinin is one of the main components of the silymarin complex, a standardized mixture obtained from the fruits of Silybum marianum commonly known as milk thistle. Silibinin has anti-inflammatory ${ }^{127}$ and neuroprotective properties $^{131-133}$ and has also been used medically for therapeutic intervention in hepatic disorders. ${ }^{134} \mathrm{~A}$ co-drug of Tacrine and Silibinin was developed, linked via a succinimide hexamethylene bridge (compound 9a, Figure 12). This compound was tested for AChE inhibition and neurotoxicity. In addition, it was evaluated for hepatotoxicity in human hepatic stellate cells (HSC). Compound 9a (Figure 12) exhibited potent AChE inhibition and neuroprotective effects. In addition, it almost eliminated the hepatotoxicity of Tacrine.

\section{Tacrine-Trolox analogues ${ }^{128}$}

Trolox is a water-soluble analogue of Vitamin E and is known to have strong antioxidant activity. ${ }^{42}$ Numerous studies indicate that Trolox can protect liver from the

\begin{tabular}{|c|c|c|c|}
\hline \multicolumn{4}{|c|}{ Table 3: Tacrine chimeric series and their activities. } \\
\hline $\begin{array}{c}\text { Sr. } \\
\text { no. }\end{array}$ & $\begin{array}{c}\text { Hybrid } \\
\text { series }\end{array}$ & Activity profile & Ref. \\
\hline 1. & $\begin{array}{c}\text { Tacrine- } \\
\text { Silibinin }\end{array}$ & $\begin{array}{c}\text { Anticholinesterase, neuroprotective, } \\
\text { no hepatotoxicity }\end{array}$ & 127 \\
\hline 2. & $\begin{array}{c}\text { Tacrine- } \\
\text { Trolox }\end{array}$ & $\begin{array}{c}\text { Anticholinesterase antioxidant, } \\
\text { neuroprotective, no hepatotoxicity }\end{array}$ & 128 \\
\hline 3. & $\begin{array}{c}\text { Tacrine- } \\
\text { Ferulic } \\
\text { acid }\end{array}$ & $\begin{array}{c}\text { Anticholinesterase, partial inhibition } \\
\text { of AChE-induced A fibril formation } \\
\text { and amyloid self-aggregation, } \\
\text { significantly lower hepatotoxicity than } \\
\text { Tacrine }\end{array}$ & 129 \\
\hline 4. & $\begin{array}{c}\text { Tacrine- } \\
\text { Rhein }\end{array}$ & $\begin{array}{c}\text { Anticholinesterase, antioxidant, } \\
\text { inhibition of AChE-induced A } \beta \\
\text { aggregation, metal chelating } \\
\text { properties, low hepatotoxicity }\end{array}$ & 130 \\
\hline
\end{tabular}

damage induced by chemical insults both in in-vivo and in-vitro conditions.

Chimeric molecules combining Tacrine with Trolox were synthesized by joining them through various linkers, resulting in identification of compounds with cholinesterase inhibition in nanomolar range as well as strong antioxidant activity. The most potent compound, compound 10a (Figure 13) in addition, also had neuroprotective effects, had good BBB penetration and hepatotoxicity much less than that of Tacrine. In addition, it also displayed neuroprotective effect against hydrogen peroxide induced PC-12 cells and had good penetration ability. Molecular modelling and kinetic studies demonstrated that this compound showed mixed-type enzyme inhibition with potential

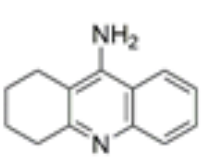

Tacrine<smiles>COc1cc([C@H]2Oc3cc([C@@H]4Oc5cc(O)cc(O)c5C(=O)[C@H]4O)ccc3O[C@H]2CO)ccc1O</smiles>

Silibinin<smiles>COc1cc([C@H]2Oc3cc([C@@H]4Oc5cc(O)cc(O)c5C(=O)[C@H]4O)ccc3O[C@H]2COC(=O)CCC(=O)NNCc2c3c(nc4ccccc24)CCCC3)ccc1O</smiles>

9a

\section{Tacrine-Silibinin hybrid}

Figure 12: Top panel- Tacrine, Silibinin Bottom panel- TacrineSilibinin chimera.<smiles>Nc1c2c(nc3ccccc13)CCCC2</smiles>

Tacrine<smiles>Cc1c(C)c2c(c(C)c1O)CCC(C)(C(=O)O)O2</smiles>

Trolox<smiles>Cc1c(C)c2c(c(C)c1O)CC(C)(C(=O)NCCCCCCNc1c3c(nc4ccccc14)CCCC3)CC2</smiles>

\section{Tacrine-Trolox hybrid}

Figure 13: Top panel- Tacrine, Bottom panel- Tacrine-Trolox chimera. 
for additional binding to the peripheral anionic site of AChE along with the catalytic site.

\section{Tacrine-Ferulic acid analogues ${ }^{129}$}

Ferulic acid is a naturally occurring phenolic acid, abundantly found in medicinal plants such as Triticum aestivum or Eucalyptus globules. Ferulic acid scaffolds and esters have been reported to show strong antioxidant and hepatoprotective activity ${ }^{135}$ as well as inhibition of $\mathrm{A} \beta_{1-42}$ in the brain when investigated on mice. ${ }^{136,137}$

Novel Tacrine-Ferulic acid chimeric molecules were developed in an attempt to combine the AChE inhibitory properties of Tacrine and the in-vitro inhibitory effects on $A \beta$ fibril formation and aggregation reported for the ferulic acid nucleus. The aromatic hydroxy group of Ferulic acid was capped with various substituted benzyl groups. The benzyloxy ferulic acid analogues were coupled to Tacrine via a functionalized amide linkage. The most active hybrid molecule, compound 11a (Figure 14) had multiple methyl substituents on the benzyl ring and showed nanomolar inhibitory potency against AChE, as well as an ability to partially inhibit amyloid self-aggregation.

The authors employed molecular docking studies in order to determine the probable binding mode of the hybrid molecules. The Tacrine fragment was seen to occupy its place at the catalytic site, engaging in stacking interactions with Trp86 and hydrogen bonding interactions with Tyr337 while the Ferulic acid moiety was found to make contact with the peripheral anionic site via hydrogen bonding interactions with Tyr 341 and stacking interactions with $\operatorname{Trp} 286$ and Tyr341. In<smiles>Nc1c2c(nc3ccccc13)CCCC2</smiles><smiles>COc1cc(/C=C/C(=O)O)ccc1O</smiles>

Tacrine

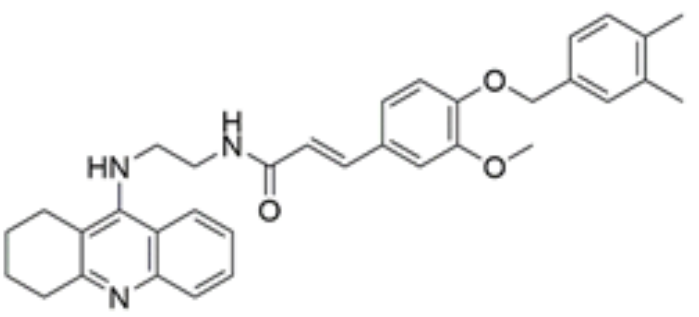

11a

\section{Tacrine - Ferulic acid hybrid}

Figure 14: Top panel- Tacrine, Ferulic acid, Bottom panelTacrine-Ferulic acid chimera. addition, compound 11a had a better safety profile and showed no significantly hepatotoxicity when tested by the ALT and ASAT activity assay.

\section{Tacrine-Rhein analogues ${ }^{130}$}

Rhein (4,5-dihydroxyanthraquinone-2-carboxylic acid) is the active component of rhubarb plant (Rheum officinale), a traditional Chinese herb. It is used to treat chronic liver disease, has hepatoprotective effect, prevents injury in hepatic cells and development of hepatic fibrosis in rats. ${ }^{138,139}$

Researchers developed a series of Tacrine-Rhein hybrids, most of which inhibited AChE in the nanomolar range. Compound 13a (Figure 15) was five-fold more active than Tacrine, inhibited AChE-induced A $\beta$ aggregation, exhibited metal chelating properties and had low hepatotoxicity. ${ }^{130}$

Kinetic evaluation supported by molecular modelling studies revealed the compounds to interact with $\mathrm{AChE}$ via a mixed type of enzyme inhibition, with capability of binding to both the active catalytic site and the peripheral anionic sites of AChE.

\section{CONCLUSION}

The chimeric strategy for design of multifunctional agents, which combines different biological activities in a single molecule, holds a lot of promise for the development of novel drugs in the treatment of multitarget neurodegenerative diseases like $\mathrm{AD}$. One of the main drawbacks of currently available FDA-approved drugs for the treatment of $\mathrm{AD}$ is that they target only a<smiles>Nc1c2c(nc3ccccc13)CCCC2</smiles><smiles>O=C(O)c1cc(O)c2c(c1)C(=O)c1cccc(O)c1C2=O</smiles>

Tacrine Rhein

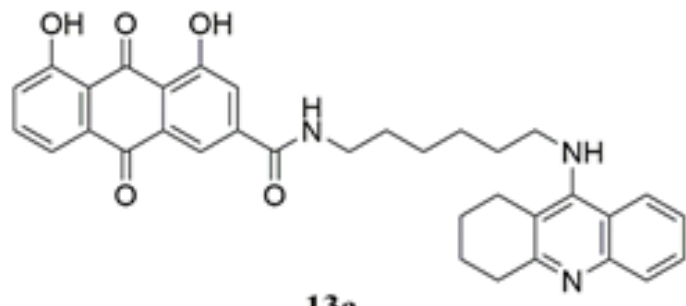

$13 \mathbf{a}$

Figure 15: Top panel-Tacrine, Rhein, Bottom panel- TacrineRhein chimera. 
single mechanism in the development of this multifactorial disease. Several natural molecules have a plethora of activities such as antioxidant, anti-inflammatory and neuroprotective properties which are vital for complete cure of patients with AD. Hybridization of these molecules with FDA-approved cholinesterase inhibitors would expand the anti-AD spectrum by creating molecular entities which address most of the causal hypotheses of AD development.

The rational design of chimeric molecules for multipletargeted clinical use presents its own set of challenges such as achieving a balanced overall activity profile, excluding undesired off-target effects and toxicity while retaining good drug-like properties in the designed molecules. Rational drug design strategies, especially structure-based in silico techniques and binding interaction mapping of parent molecules can be used to identify molecular determinants for focused activities.

The crystallographic structure of AChE reveals that it has a narrow $20 \AA$ gorge, containing two binding sites: the catalytic active site (CAS) at the bottom and the peripheral anionic site (PAS) near the entrance of the gorge. Binding to the CAS is crucial to inhibition of the AChE enzyme. Study of the active site of AChE complexes bound to relatively larger-sized inhibitors like Donepezil and Rivastigmine has helped to identify the pharmacophoric units of these molecules, which make contact with the catalytic active site of AChE. Retaining these fragments viz benzyl piperidine fragment of Donepezil and carbamoyl fragment of Rivastigmine and replacing the

\begin{tabular}{|c|c|c|c|c|c|c|c|c|}
\hline \multirow[t]{2}{*}{ Hybrid series } & \multirow[t]{2}{*}{$\mathrm{Cmp}$} & \multirow[t]{2}{*}{ AChEi } & \multirow[t]{2}{*}{ DPPH } & \multirow[t]{2}{*}{ ORAC } & \multicolumn{3}{|c|}{$\%$ inhibition of $\mathrm{Ab}$ aggregation } & \multirow[t]{2}{*}{ Ref } \\
\hline & & & & & Self-induced & Metal-induced & AChE-induced & \\
\hline \multirow{3}{*}{$\begin{array}{l}\text { Donepezil- } \\
\text { Ferulic acid }\end{array}$} & $1 \mathrm{a}$ & $0.46^{*}$ & $49.41^{\mathrm{a}}$ & - & - & - & - & \multirow{3}{*}{40} \\
\hline & $1 \mathrm{~b}$ & $16.74^{*}$ & $46.66^{a}$ & - & - & - & - & \\
\hline & $1 \mathrm{c}$ & $>30^{*}$ & $45.38^{a}$ & - & - & - & - & \\
\hline \multirow{3}{*}{$\begin{array}{l}\text { Donepezil- } \\
\text { Genistein }\end{array}$} & $2 a$ & $4.98^{*}$ & - & 1.2 & 34.3 & 72.1 & 18.7 & \multirow{3}{*}{34} \\
\hline & $2 b$ & $15.9^{*}$ & - & 1.1 & 24.6 & 71.9 & 22 & \\
\hline & $2 c$ & $0.14^{*}$ & - & 0.3 & 35 & 77.8 & 36.2 & \\
\hline \multirow{3}{*}{$\begin{array}{l}\text { Donepezil- } \\
\text { Melatonin }\end{array}$} & 3a & $16.8^{*}$ & - & 1.3 & 60.5 & - & - & \multirow{3}{*}{41} \\
\hline & $3 b$ & $2.2^{*}$ & - & 3.38 & 40.5 & - & - & \\
\hline & $3 c$ & $0.193^{*}$ & - & 3.28 & 56.3 & - & - & \\
\hline Donepezil-Trolox & $4 a$ & $0.31^{*}$ & $43.33^{b}$ & 1.62 & 56.3 & 63.9 & - & 42 \\
\hline \multirow{8}{*}{$\begin{array}{l}\text { Rivastigmine- } \\
\text { hydroxy } \\
\text { cinnamic acid }\end{array}$} & $5 a$ & $16.75^{\#}$ & $37^{b}$ & - & 73.2 & - & - & \multirow{8}{*}{106} \\
\hline & $5 b$ & $24.62^{\#}$ & $19.5^{b}$ & - & 13.2 & - & - & \\
\hline & $5 c$ & $23.3^{\#}$ & $69.7^{b}$ & - & 77.6 & - & - & \\
\hline & $5 d$ & $34.28^{\#}$ & $17.9^{b}$ & - & 3.2 & - & - & \\
\hline & $5 e$ & 23.99 \# & $51.7^{b}$ & - & 85.3 & - & - & \\
\hline & $5 f$ & 70.66 \# & $18.1^{\mathrm{b}}$ & - & 2.2 & - & - & \\
\hline & $5 g$ & $16.4^{\#}$ & $64.7^{\mathrm{b}}$ & - & 82.5 & - & - & \\
\hline & $5 \mathrm{~h}$ & $14.93^{\#}$ & $24.1^{b}$ & - & 2.2 & - & - & \\
\hline $\begin{array}{c}\text { Rivastigmine- } \\
\text { Apigenin }\end{array}$ & $6 a$ & $4.7^{*}$ & - & 1.3 & 77.9 & 78.9 & 73.6 & 105 \\
\hline \multirow{3}{*}{$\begin{array}{l}\text { Rivastigmine- } \\
\text { scutellarin }\end{array}$} & $7 a$ & $1.54^{*}$ & - & 0.34 & - & - & - & \multirow{3}{*}{103} \\
\hline & $7 b$ & $0.34^{*}$ & - & 0.36 & - & - & - & \\
\hline & $8 a$ & $0.57^{*}$ & - & 1.3 & - & - & - & \\
\hline Tacrine-Silibinin & $9 a$ & 0.054 * & - & - & - & - & - & 127 \\
\hline Tacrine-Trolox & $10 a$ & $9.8^{*}$ & - & - & - & - & - & 128 \\
\hline $\begin{array}{l}\text { Tacrine-Ferulic } \\
\text { acid }\end{array}$ & $11 a$ & $37^{*}$ & - & - & 65.49 & - & - & 129 \\
\hline Tacrine-Rhein & $13 a$ & $27.3^{*}$ & - & - & - & - & 70.2 & 130 \\
\hline
\end{tabular}


non-pharmacophoric parts with various natural bioactive fragments which possess antioxidant, anti-inflammatory, metal chelation and neuroprotective activities has helped bring in other $\mathrm{AD}$-relevant biological activities in these AChE inhibitors. These non-pharmacophoric fragments make contact with the peripheral anionic site of the AChE active site and have been optimized to improve the overall binding interactions of the molecules within the AChE binding pocket. Many of the resultant hybrid dualsite binders show mixed type of enzyme inhibition and have been found to have better AChE binding potencies than the parent molecule in addition to having multiple biological functionalities.

Biochemical experiments have reported that $\mathrm{AChE}$ facilitates amyloid fibril formation by interacting through the PAS of the enzyme, forming stable AChE-A $\beta$ complexes, which are more toxic than single $A \beta$ peptides. Therefore, dual-site inhibitors that interact with both CAS and PAS appear to be a very effective therapeutic approach, since they can enhance cognition and slow the rate of A $\beta$-related neurodegeneration.

Tacrine, on the other hand is a relatively small-sized compound and presents opportunities for retaining the entire molecule, while coupling it with bioactive fragments like Silibinin, Trolox, Ferulic acid and Rhein via customized linkers of optimal length. The hybridization approach also allows the introduction of moieties which can counteract the hepatoxicity of this potent but toxic molecule. Molecules with known hepatoprotective properties have been successfully coupled with Tacrine to develop potentially safe, multifunctional hybrid molecules for the holistic treatment of AD.

In this review we have compiled several chimeric series of multifunctional molecules and rationalized their structure activity relationships in depth. The experimental biological data has been tabulated in Table 4. There is currently limited clinical evidence for these chimeric molecules. Nevertheless, multiple insights have been drawn from these studies, which can be used concomitantly to give focused direction to the development of novel, broadspectrum, effective and safe molecules which can cause complete cure of Alzheimer's disease.

\section{ACKNOWLEDGEMENT}

The authors acknowledge SVKM's Dr. Bhanuben Nanavati College of Pharmacy, Mumbai for providing all the necessary facilities during the article preparation.

\section{CONFLICT OF INTEREST}

The authors declare no conflict of interest.

\section{ABBREVIATIONS}

AAPH: 2'-azobis-(2-amidinopropane) dihydrochloride; ABTS-: 2, 20-azinobis- (3-ethyl benzothiazoline-6sulfonate) radical ions; AChE: Acetylcholinesterase; AD: Alzheimer's disease; AFMK: N (1)-acetyl-N (2)-formyl5-methoxy kynuramine; ALT: Alanine transaminase; AMK: $N$ (1)-acetyl-5-methoxy kynuramine; APP: Amyloid Precursor Protein; AST: Aspartate transaminase; $\mathbf{A} \boldsymbol{\beta}: \boldsymbol{\beta}$-amyloid protein peptides; $\mathbf{A} \boldsymbol{\beta} \mathbf{O}$ : A $\beta$ Oligomers; BBB: Blood Brain Barrier; BuChE: Butyrylcholinesterase; CAS: Catalytic active site; CNS: Central nervous system; DMSO: Dimethyl sulfoxide; DPPH: 1,1-diphenyl-2-picryl hydrazyl ( $\alpha, \alpha$-diphenyl$\beta$-picraylhydrazyl); HEPES: 4-(2-hydroxy ethyl)-1piperazine ethane sulfonic acid; HSC: Human Hepatic Stellate Cells; HuAChE: Human Acetylcholinesterase; LPS: Lipopolysaccharide; MTDL: Multi-Target Directed Ligands; MTT: 3-(4, 5-dimethyl thiazol2-yl)-2, 5-diphenyl tetrazolium bromide; NAP: S-3- [1(dimethyl amino) ethyl] phenol; NFT: Neurofibrillary tangles; NMDA: N-Methyl-D-Aspartate; ORAC: Oxygen Radical Absorbance Capacity; PAS: Peripheral anionic site; PDB: Protein data bank; ROS: Reactive Oxygen Species; TEAC: Trolox Equivalent Antioxidant Capacity; TEM: Transmission Electron microscopy; ThT: Thioflavin-T; Trp: Tryptophan; Tyr: Tyrosine.

\section{REFERENCES}

1. Sun Y, Chen J, Chen X, Huang L, Li X. Inhibition of cholinesterase and monoamine oxidase-B activity by Tacrine-Homoiso flavonoid hybrids. Bioorganic Med Chem. 2013;21(23):7406-17.

2. Araújo JQ, Lima JA, Pinto ADC, DeAlencastro RB, Albuquerque MG. Docking of the alkaloid geissospermine into acetylcholinesterase: A natural scaffold targeting the treatment of Alzheimer's disease. J Mol Model. 2011;17(6):140112.

3. Calcul L, Zhang B, Jinwal UK, Dickey CA, Baker BJ. Natural products as a rich source of tau-targeting drugs for Alzheimers disease. Future Med Chem. 2012;4(13):1751-61.

4. Report AA. Alzheimer's disease facts and figures. Alzheimer's Dement. 2020;16(3):391-460.

5. Zhang X, He X, Chen Q, Lu J, Rapposelli S, Pi R. A review on the hybrids of hydroxycinnamic acid as multi-target-directed ligands against Alzheimer's disease. Bioorganic Med Chem. 2018;26(3):543-50. Available from: https:// doi.org/10.1016/j.bmc.2017.12.042

6. Zhang C, Du QY, DiChen L, Wu WH, Liao SY, Yu LH, et al. Design, synthesis and evaluation of novel tacrine-multialkoxybenzene hybrids as multi-targeted compounds against Alzheimer's disease. Eur J Med Chem. 2016;116:200-9.

7. Munoz-Torrero D, Camps P. Dimeric and Hybrid Anti-Alzheimer Drug Candidates. Curr Med Chem. 2006;13(4):399-422.

8. Muñoz-Torrero D. Acetylcholinesterase Inhibitors as Disease-Modifying Therapies for Alzheimer's Disease. Front Med Chem. 2008;15(24):2433-55.

9. Rizzo S, Rivière C, Piazzi L, Bisi A, Gobbi S, Bartolini M, et al. Benzofuranbased hybrid compounds for the inhibition of cholinesterase activity, $\beta$ amyloid aggregation and $A \beta$ neurotoxicity. J Med Chem. 2008;51(10):2883-6.

10. Singh M, Kaur M, Chadha N, Silakari O. Hybrids: A new paradigm to treat Alzheimer's disease. Mol Divers. 2016;20(1):271-97. 
11. Singh M, Kaur M, Kukreja H, Chugh R, Silakari O, Singh D. Acetylcholinesterase inhibitors as Alzheimer therapy: From nerve toxins to neuroprotection. Eur J Med Chem. 2013;70:165-88.

12. Niedzielska E, Smaga I, Gawlik M, Moniczewski A, Stankowicz P, Pera J, et al. Oxidative Stress in Neurodegenerative Diseases. Mol Neurobiol. 2016;53(6):4094-125.

13. Butterfield D. Amyloid and \#946;-Peptide [1-42]-Associated Free RadicalInduced Oxidative Stress and Neurodegeneration in Alzheimers Disease Brain: Mechanisms and Consequences. Curr Med Chem. 2005;10(24):26519.

14. Bush Al, Tanzi RE. Therapeutics for Alzheimer's disease Based on the Metal Hypothesis. 2008;5(3):421-32.

15. Zatta P, Drago D, Bolognin S, Sensi SL. Alzheimer's disease, metal ions and metal homeostatic therapy. Trends Pharmacol Sci. 2009;30(7):346-55.

16. Barnham KJ, Bush Al. Metals in Alzheimer's and Parkinson's Diseases. Curr Opin Chem Biol. 2008;12(2):222-8.

17. Amit T, Avramovich-Tirosh $\mathrm{Y}$, Youdim $\mathrm{MBH}$, Mandel S. Targeting multiple Alzheimer's disease etiologies with multimodal neuroprotective and neurorestorative iron chelators. FASEB J. 2008;22(5):1296-305.

18. Zheng $\mathrm{H}$, Youdim $\mathrm{MBH}$, Fridkin M. Site-activated multifunctional chelator with acetylcholinesterase and neuroprotective-neurorestorative moieties for Alzheimer's therapy. J Med Chem. 2009;52(14):4095-8.

19. Sharma P, Srivastava P, Seth A, Tripathi PN, Banerjee AG. Comprehensive review of mechanisms of pathogenesis involved in Alzheimer's disease and potential therapeutic strategies. Prog Neurobiol. 2019;174:53-89.

20. Crismon ML. Tacrine: First drug approved for alzheimer's disease. Ann Pharmacother. 1994;28(6):744-51.

21. Bryson HM, Benfield P. Ad is New Drug Profile Donepezil. Drugs \& Aging 1997;10(3):234-9.

22. Polinsky RJ. Clinical pharmacology of rivastigmine: A new-generation acetylcholinesterase inhibitor for the treatment of Alzheimer's disease. Clin Ther. 1998;20(4):634-47.

23. Shimohama S. Galantamine. Nihon Rinsho. 2011;69(Suppl 1(Pt 2):31-5.

24. Parsons CG, Stöffler A, Danysz W. Memantine: A NMDA receptor antagonist that improves memory by restoration of homeostasis in the glutamatergic system - too little activation is bad, too much is even worse. Neuropharmacology. 2007;53(6):699-723.

25. Bajda M, Guzior N, Ignasik M, Malawska B. Multi-Target-Directed Ligands in Alzheimer's Disease Treatment. Curr Med Chem. 2011;18(32):4949-75.

26. Pisani L, Catto M, Leonetti F, Nicolotti O, Stefanachi A, Campagna F, et al. Targeting Monoamine Oxidases with Multipotent Ligands: An Emerging Strategy in the Search of New Drugs Against Neurodegenerative Diseases. Curr Med Chem. 2012;18(30):4568-87.

27. Morphy R, Rankovic Z. Designed multiple ligands. An emerging drug discovery paradigm. J Med Chem. 2005;48(21):6523-43.

28. Youdim MBH, Buccafusco JJ. Multi-functional drugs for various CNS targets in the treatment of neurodegenerative disorders. Trends Pharmacol Sci. 2005;26(1):27-35.

29. Schmitt B, Bernhardt T, Moeller HJ, Heuser I, Frölich L. Combination therapy in Alzheimer's disease: A review of current evidence. CNS Drugs. 2004;18(13):827-44.

30. Miccadei S, DiVenere D, Cardinali A, Romano F, Durazzo A, Foddai MS, et al. Antioxidative and apoptotic properties of polyphenolic extracts from edible part of artichoke (Cynara scolymus L.) on cultured rat hepatocytes and on human hepatoma cells. Nutr Cancer. 2008;60(2):276-83.

31. D'Evoli L, Morroni F, Lombardi-Boccia G, Lucarini M, Hrelia P, Cantelli-Forti $\mathrm{G}$, et al. Red chicory (Cichorium intybus L. cultivar) as a potential source of antioxidant anthocyanins for intestinal health. Oxid Med Cell Longev. 2013;18.

32. Azzini E, Maiani G, Garaguso I, Polito A, Foddai MS, Venneria E, et al. The potential health benefits of polyphenol-rich extracts from Cichorium intybus $\mathrm{L}$. studied on caco-2 cells model. Oxid Med Cell Longev. 2016;1-9.

33. Abenavoli L, Izzo AA, Milić N, Cicala C, Santini A, Capasso R. Milk thistle (Silybum marianum): A concise overview on its chemistry, pharmacological and nutraceutical uses in liver diseases. Phyther Res. 2018;32(11):2202-13.

34. Qiang X, Sang Z, Yuan W, Li Y, Liu Q, Bai P, et al. Design, synthesis and evaluation of genistein-O-alkylbenzylamines as potential multifunctional agents for the treatment of Alzheimer's disease. Eur J Med Chem. 2014;76:31431. Available from: http://dx.doi.org/10.1016/j.ejmech.2014.02.045

35. Wang ZM, Cai P, Liu QH, Xu DQ, Yang XL, Wu JJ, et al. Rational modification of donepezil as multifunctional acetylcholinesterase inhibitors for the treatment of Alzheimer's disease. Eur J Med Chem. 2016;123:282-97.

36. Darreh-Shori T. Effects of Cholinesterase Inhibitors on the Activities and Protein Levels of Cholinesterases in the Cerebrospinal Fluid of Patients with Alzheimer's disease: A Review of Recent Clinical Studies. Curr Alzheimer Res. 2009;999(999):1-6.

37. Kumar A, Sharma S. Donepezil. In: Stat Pearls Treasure Island (FL): Stat Pearls Publishing. 2020. Available from: https://www.ncbi.nlm.nih.gov/books/ NBK513257/

38. Yerdelen KO, Koca M, Anil B, Sevindik H, Kasap Z, Halici Z, et al. Synthesis of donepezil-based multifunctional agents for the treatment of Alzheimer's disease. Bioorganic Med Chem Lett. 2015;25(23):5576-82. Available from: http://dx.doi.org/10.1016/j.bmcl.2015.10.051

39. Cheung J, Rudolph MJ, Burshteyn F, Cassidy MS, Gary EN, Love J, et al. Structures of human acetylcholinesterase in complex with pharmacologically important ligands. J Med Chem. 2012;55(22):10282-6.

40. Dias KST, DePaula CT, DosSantos T, Souza INO, Boni MS, Guimarães MJR, et al. Design, synthesis and evaluation of novel feruloyl-donepezil hybrids as potential multitarget drugs for the treatment of Alzheimer's disease. Eur J Med Chem. 2017;130:440-57. Available from: http://dx.doi.org/10.1016/j. ejmech.2017.02.043

41. Wang J, Wang ZM, Li XM, Li F, Wu JJ, Kong LY, et al. Synthesis and evaluation of multi-target-directed ligands for the treatment of Alzheimer's disease based on the fusion of donepezil and melatonin. Bioorganic Med Chem. 2016;24(18):4324-38. Available from: http://dx.doi.org/10.1016/j. bmc.2016.07.025

42. Cai P, Fang SQ, Yang XL, Wu JJ, Liu QH, Hong H, et al. Rational Design and Multibiological Profiling of Novel Donepezil-Trolox Hybrids against Alzheimer's Disease, with Cholinergic, Antioxidant, Neuroprotective and Cognition Enhancing Properties. ACS Chem Neurosci. 2017;8(11):2496-511.

43. Zhao Z, Moghadasian MH. Chemistry, natural sources, dietary intake and pharmacokinetic properties of ferulic acid: A review. Food Chem. 2008;109(4):691-702.

44. Kumar N, Pruthi V. Potential applications of ferulic acid from natural sources. Biotechnol Reports. 2014;4(1):86-93. Available from: http://dx.doi. org/10.1016/j.btre.2014.09.002

45. Gélinas P, McKinnon CM. Effect of wheat variety, farming site and breadbaking on total phenolics. Int J Food Sci Technol. 2006;41(3):329-32.

46. Beejmohun V, Fliniaux O, Grand É, Lamblin F, Bensaddek L, Christen P, et al. Microwave-assisted extraction of the main phenolic compounds in flaxseed. Phytochem Anal. 2007;18(4):275-82.

47. Quinde-Axtell Z, Baik BK. Phenolic compounds of barley grain and their implication in food product discoloration. J Agric Food Chem. 2006;54(26):9978-84.

48. Catto M, Pisani L, Leonetti F, Nicolotti O, Pesce P, Stefanachi A, et al. Design, synthesis and biological evaluation of coumarin alkylamines as potent and selective dual binding site inhibitors of acetylcholinesterase. Bioorganic Med Chem. 2013;21(1):146-52. Available from: http://dx.doi.org/10.1016/j. bmc.2012.10.045

49. Bonda DJ, Wang X, Perry G, Nunomura A, Tabaton M, Zhu X, et al. Oxidative stress in Alzheimer disease: A possibility for prevention. Neuropharmacology. 2010;59(4-5):290-4. Available from: http://dx.doi.org/10.1016/j. neuropharm.2010.04.005

50. Alam MN, Bristi NJ, Rafiquzzaman M. Review on in vivo and in vitro methods evaluation of antioxidant activity. Saudi Pharm J. 2013;21(2):143-52. Available from: http://dx.doi.org/10.1016/j.jsps.2012.05.002

51. Karadag A, Ozcelik B, Saner S. Review of methods to determine antioxidant capacities. Food Anal Methods. 2009;2(1):41-60.

52. Mezeiova E, Spilovska K, Nepovimova E, Gorecki L, Soukup O, Dolezal R, et al. Profiling donepezil template into multipotent hybrids with antioxidant properties. J Enzyme Inhib Med Chem. 2018;33(1):583-606. Available from: https://doi.org/10.1080/14756366.2018.1443326

53. Nimse SB, Pal D. Free radicals, natural antioxidants and their reaction mechanisms. RSC Adv. 2015;5(35):27986-8006. Available from: http://dx.doi. org/10.1039/C4RA13315C 
54. Scherer R, Godoy HT. Antioxidant activity index (AAI) by the 2,2-diphenyl-1picrylhydrazyl method. Food Chem. 2009;112(3):654-8.

55. Heppner FL, Ransohoff RM, Becher B. Immune attack: The role of inflammation in Alzheimer disease. Nat Rev Neurosci. 2015;16(6):358-72. Available from: http://dx.doi.org/10.1038/nrn3880

56. Heneka MT, Carson MJ, ElKhoury J, Landreth GE, Brosseron F, Feinstein $\mathrm{DL}$, et al. Neuroinflammation in Alzheimer's disease. Lancet Neurol. 2015;14(4):388-405

57. Holmes C. Review: Systemic inflammation and Alzheimer's disease. Neuropathol Appl Neurobiol. 2013;39(1):51-68.

58. Geng JG. Directional migration of leukocytes: Their pathological roles in inflammation and strategies for development of anti-inflammatory therapies. Cell Res. 2001;11(2):85-8.

59. García-Ramallo E, Marques T, Prats N, Beleta J, Kunkel SL, Godessart N. Resident Cell Chemokine Expression Serves as the Major Mechanism for Leukocyte Recruitment during Local Inflammation. J Immunol. 2002;169(11):6467-73.

60. Cunha TM, Verri WA, Silva JS, Poole S, Cunha FQ, Ferreira SH. A cascade of cytokines mediates mechanical inflammatory hypernociception in mice. Proc Natl Acad Sci U S A. 2005;102(5):1755-60.

61. McNamara CR, Mandel-Brehm J, Bautista DM, Siemens J, Deranian KL, Zhao M, et al. TRPA1 mediates formalin-induced pain. Proc Natl Acad Sci U S A. 2007;104(33):13525-30.

62. DeClarice CV, Vanessa GR, DeAdolfo OA, DaCristina CO, Lindisley FG, Lucienir PD, et al. Antinociceptive effects of Maytenus imbricata Mart. ex. Reissek (Celastraceae) root extract and its tingenone constituent. J Med Plants Res. 2014;8(1):68-76.

63. Santos ARS, Calixto JB. Further evidence for the involvement of tachykinin receptor subtypes in formalin and capsaicin models of pain in mice. Neuropeptides. 1997;31(4):381-9.

64. Jomova K, Vondrakova D, Lawson M, Valko M. Metals, oxidative stress and neurodegenerative disorders. Mol Cell Biochem. 2010;345(1-2):91-104.

65. González-Domínguez R, García-Barrera T, Gómez-Ariza JL. Homeostasis of metals in the progression of Alzheimer's disease. Bio Metals. 2014;27(3):53949.

66. Chen SY, Chen Y, Li YP, Chen SH, Tan JH, Ou TM, et al. Design, synthesis and biological evaluation of curcumin analogues as multifunctional agents for the treatment of Alzheimer's disease. Bioorganic Med Chem. 2011;19(18):5596604. Available from: http://dx.doi.org/10.1016/j.bmc.2011.07.033

67. Salahuddin P, Fatima MT, Abdelhameed AS, Nusrat S, Khan RH. Structure of amyloid oligomers and their mechanisms of toxicities: Targeting amyloid oligomers using novel therapeutic approaches. Eur J Med Chem. 2016;114:4158. Available from: http://dx.doi.org/10.1016/j.ejmech.2016.02.065

68. Rauk A. Why is the amyloid beta peptide of Alzheimer's disease neurotoxic?. Dalt Trans. 2008;(10):1273-82.

69. Budni J, Feijó DP, Batista-Silva H, Garcez ML, Mina F, Belletini-Santos T, et al. Lithium and memantine improve spatial memory impairment and neuroinflammation induced by $\beta$-amyloid 1-42 oligomers in rats. Neurobiol Learn Mem. 2017;141:84-92. Available from: http://dx.doi.org/10.1016/j. nIm.2017.03.017

70. Haass C, Selkoe DJ. Soluble protein oligomers in neurodegeneration: Lessons from the Alzheimer's amyloid $\beta$-peptide. Nat Rev Mol Cell Biol. 2007;8(2):101-12.

71. Rüfer CE, Kulling SE. Antioxidant activity of isoflavones and their major metabolites using different in vitro assays. J Agric Food Chem. 2006;54(8):2926-31.

72. Ma W, Ding B, Yu H, Yuan L, Xi Y, Xiao R. Genistein alleviates $\beta$-amyloidinduced inflammatory damage through regulating toll-like receptor $4 /$ nuclear factor KB. J Med Food. 2015;18(3):273-9.

73. Mira L, Fernandez MT, Santos M, Rocha R, Florêncio MH, Jennings KR. Interactions of flavonoids with iron and copper ions: A mechanism for their antioxidant activity. Free Radic Res. 2002;36(11):1199-208.

74. Zhao B. Natural antioxidants for neurodegenerative diseases. Mol Neurobiol. 2005;31(1-3):283-93.

75. Bang OY, Hong HS, Kim DH, Kim H, Boo JH, Huh K, et al. Neuroprotective effect of genistein against beta amyloid-induced neurotoxicity. Neurobiol Dis. 2004;16(1):21-8.
76. Pisoschi AM, Negulescu GP. Methods for Total Antioxidant Activity Determination: A Review. Biochem Anal Biochem. 2012;01(01):1-10.

77. Thaipong K, Boonprakob U, Crosby K, Cisneros-Zevallos L, Hawkins BD. Comparison of ABTS, DPPH, FRAP and ORAC assays for estimating antioxidant activity from guava fruit extracts. J Food Compos Anal. 2006;19(67):669-75.

78. Denev P, Ciz M, Ambrozova G, Lojek A, Yanakieva I, Kratchanova M. Solidphase extraction of berries' anthocyanins and evaluation of their antioxidative properties. Food Chem. 2010;123(4):1055-61. Available from: http://dx.doi. org/10.1016/j.foodchem.2010.05.061

79. Bisby RH, Brooke R, Navaratnam S. Effect of antioxidant oxidation potential in the oxygen radical absorption capacity (ORAC) assay. Food Chem. 2008;108(3):1002-7.

80. Reiter RJ, Acuña-Castroviejo D, Tan DX, Burkhardt S. Free radical-mediated molecular damage. Mechanisms for the protective actions of melatonin in the central nervous system. Ann N Y Acad Sci. 2001;939(1):200-15. Available from: http://www.ncbi.nlm.nih.gov/pubmed/11462772

81. Paradies G, Petrosillo G, Paradies V, Reiter RJ, Ruggiero FM. Melatonin, cardiolipin and mitochondrial bioenergetics in health and disease. J Pineal Res. 2010;48(4):297-310.

82. Romero A, Egea J, García AG, López MG. Synergistic neuroprotective effect of combined low concentrations of galantamine and melatonin against oxidative stress in SH-SY5Y neuroblastoma cells. J Pineal Res. 2010;49(2):141-8.

83. Hardeland R, Tan DX, Reiter RJ. Kynuramines, metabolites of melatonin and other indoles: The resurrection of an almost forgotten class of biogenic amines. J Pineal Res. 2009;47(2):109-26.

84. Deng YQ, Xu GG, Duan P, Zhang Q, Wang JZ. Effects of melatonin on wortmannin-induced tau hyper phosphorylation. Acta Pharmacol Sin. 2005;26(5):519-26.

85. Li SP, Deng YQ, Wang XC, Wang YP, Wang JZ. Melatonin protects SH-SY5Y neuroblastoma cells from calyculin A-induced neurofilament impairment and neurotoxicity. J Pineal Res. 2004;36(3):186-91.

86. Li XC, Wang ZF, Zhang JX, Wang Q, Wang JZ. Effect of melatonin on calyculin A-induced tau hyper phosphorylation. Eur J Pharmacol. 2005;510(1-2):25-30.

87. Wang XC, Zhang J, Yu X, Han L, Zhou ZT, Zhang Y, et al. Prevention of isoproterenol-induced tau hyper phosphorylation by melatonin in the rat. Sheng Li Xue Bao. 2005;57(1):7-12.

88. Wang DL, Ling ZQ, Cao FY, Zhu LQ, Wang JZ. Melatonin attenuates isoproterenol-induced protein kinase: A over activation and tau hyper phosphorylation in rat brain. J Pineal Res. 2004;37(1):11-6.

89. Yang X, Yang Y, Fu Z, Li Y, Feng J, Luo J, et al. Melatonin ameliorates Alzheimer-like pathological changes and spatial memory retention impairment induced by calyculin A. J Psychopharmacol. 2011;25(8):1118-25.

90. Poeggeler B, Miravalle L, Zagorski MG, Wisniewski T, Chyan YJ, Zhang Y, et al. Melatonin reverses the profibrillogenic activity of apolipoprotein E4 on the alzheimer amyloid A $\beta$ peptidet. Biochemistry. 2001;40(49):14995-5001.

91. Skribanek Z, Balspiri L, Mk M. Interaction between synthetic amyloid- $\beta$ speptide (1-40) and its aggregation inhibitors studied by electrospray ionization mass spectrometry. J Mass Spectrom. 2001;36(11):1226-9.

92. Pappolla M, Bozner P, Soto C, Shao H, Robakis NK, Frangione B, et al. Inhibition of Alzheimer b -Fibrillogenesis by Melatonin. Biochemistry. 1998;273(13):7185-8.

93. Johns JR, Platts JA. Theoretical insight into the antioxidant properties of melatonin and derivatives. Org Biomol Chem. 2014;12(39):7820-7.

94. Ellman GL, Courtney KD, Andres V, Featherstone RM. A new and rapid colorimetric determination of acetyl cholinesterase activity. Biochem Pharmacol. 1961;7(2):88-95.

95. Nepovimova E, Uliassi E, Korabecny J, Peña-Altamira LE, Samez S, Pesaresi A, et al. Multitarget drug design strategy: Quinone-tacrine hybrids designed to block amyloid- $\beta$ aggregation and to exert anticholinesterase and antioxidant effects. J Med Chem. 2014;57(20):8576-89.

96. Sharma AK, Pavlova ST, Kim J, Finkelstein D, Hawco NJ, Rath NP, et al. Bifunctional compounds for controlling metal-mediated aggregation of the $A \beta$ 42 peptide. J Am Chem Soc. 2012;134(15):6625-36.

97. Lu C, Guo Y, Yan J, Luo Z, Luo H, Bin YM, et al. Design, synthesis and evaluation of multitarget-directed resveratrol derivatives for the treatment of Alzheimer's disease. J Med Chem. 2013;56(14):5843-59. 
98. Pisani L, Farina R, Catto M, lacobazzi RM, Nicolotti O, Cellamare $\mathrm{S}$, et al. Exploring Basic Tail Modifications of Coumarin-Based Dual Acetylcholinesterase-Monoamine Oxidase B Inhibitors: Identification of Water-Soluble, Brain-Permeant Neuroprotective Multitarget Agents. J Med Chem. 2016;59(14):6791-806.

99. Block ML, Zecca L, Hong JS. Microglia-mediated neurotoxicity: Uncovering the molecular mechanisms. Nat Rev Neurosci. 2007;8(1):57-69.

100. Di L, Kerns EH, Fan K, McConnell OJ, Carter GT. High throughput artificial membrane permeability assay for blood-brain barrier. Eur J Med Chem. 2003;38(3):223-32.

101. Ukai M, Kobayashi T, Shinkai N, Kameyama T. Impairment of Passive Avoidance Response in Mice. Drugs. 1995;274:89-93.

102. Morris R. Developments of a water-maze procedure for studying spatial learning in the rat. J Neurosci Methods. 1984;11(1):47-60.

103. Sang Z, Li Y, Qiang X, Xiao G, Liu Q and Tan Z, et al. Multifunctional scutellarin-rivastigmine hybrids with cholinergic, antioxidant, biometal chelating and neuroprotective properties for the treatment of Alzheimer's disease. Bioorganic Med Chem. 2015;23(4):668-80.

104. Bacalhau P, San JAA, Goth A, Caldeira AT, Martins R, Burke AJ. Insights into (S)-rivastigmine inhibition of butyrylcholinesterase (BuChE): Molecular docking and saturation transfer difference NMR (STD-NMR). Bioorg Chem. 2016;67:105-9.

105. Sang Z, Wang K, Shi J, Cheng X, Zhu G, Wei R, et al. Apigenin-rivastigmine hybrids as multi-target-directed liagnds for the treatment of Alzheimer's disease. Eur J Med Chem. 2020;187:111958. Available from: https://doi. org/10.1016/j.ejmech.2019.111958

106. Chen Z, Digiacomo M, Tu Y, Gu Q, Wang S, Yang X, et al. Discovery of novel rivastigmine-hydroxycinnamic acid hybrids as multi-targeted agents for Alzheimer's disease. Eur J Med Chem. 2017;125:784-92. Available from: http://dx.doi.org/10.1016/j.ejmech.2016.09.052

107. Boerjan W, Ralph J, Baucher M. Lignin Biosynthesis. Annu Rev Plant Biol. 2003;54(1):519-46.

108. Santos SAO, Freire CSR, Domingues MRM, Silvestre AJD, Neto CP. Characterization of phenolic components in polar extracts of Eucalyptus globulus labill. Bark by high-performance liquid chromatography-mass spectrometry. J Agric Food Chem. 2011;59(17):9386-93.

109. Pearson JL, Lee S, Suresh H, Low M, Nang M, Singh S, et al. The Liquid Chromatographic Determination of Chlorogenic and Caffeic Acids in Xu Duan (Dipsacus asperoides) Raw Herb. ISRN Anal Chem. 2014;2014:1-6.

110. Choudhary MI, Naheed N, Abbaskhan A, Musharraf SG, Siddiqui H, Atta-urRahman. Phenolic and other constituents of fresh water fern Salvinia molesta. Phytochemistry. 2008;69(4):1018-23.

111. Lee YS, Kang YH, Jung JY, Lee S, Ohuchi K, Shin $K H$, et al. Protein glycation inhibitors from the fruiting body of Phellinus linteus. Biol Pharm Bull. 2008;31(10):1968-72.

112. Sharma A, Pachauri V, Flora SJS. Advances in multi-functional ligands and the need for metal-related pharmacology for the management of Alzheimer disease. Front Pharmacol. 2018;9(NOV):1-19.

113. Adlard PA, Manso Y, Comes G, Hidalgo J, Bush Al. Copper modulation as a therapy for Alzheimer's disease?. Int J Alzheimers Dis. 2011;1-5.

114. Huang X, Cuajungco MP, Atwood CS, Hartshorn MA, Tyndall JDA, Hanson $\mathrm{GR}$, et al. $\mathrm{Cu}(\mathrm{II})$ potentiation of Alzheimer $\mathrm{a} \beta$ neurotoxicity. Correlation with cell-free hydrogen peroxide production and metal reduction. J Biol Chem. 1999;274(52):37111-6.

115. Singh V, Sharma V, Verma V, Pandey D, Yadav SK, Maikhuri JP, et al. Apigenin manipulates the ubiquitin-proteasome system to rescue estrogen receptor- $\beta$ from degradation and induce apoptosis in prostate cancer cells. Eur J Nutr. 2015;54(8):1255-67.

116. Spilovska K, Korabecny J, Sepsova V, Jun D, Hrabinova M, Jost P, et al. Novel tacrine-scutellarin hybrids as multipotent anti-Alzheimer's agents: Design, synthesis and biological evaluation. Molecules. 2017;22(6):1-22.

117. Guo LL, Guan ZZ, Huang Y, Wang YL, Shi JS. The neurotoxicity of $\beta$-amyloid peptide toward rat brain is associated with enhanced oxidative stress, inflammation and apoptosis, all of which can be attenuated by scutellarin. Exp Toxicol Pathol. 2013;65(5):579-84. Available from: http://dx.doi.org/10.1016/j. etp.2012.05.003
118. Ghosh N, Ghosh R, Bhat ZA, Mandal V, Bachar SC, Nima ND, et al. Advances in herbal medicine for treatment of ischemic brain injury. Nat Prod Commun. 2014;9(7):1045-55.

119. Hong $\mathrm{H}$, Liu GQ. Protection against hydrogen peroxide-induced cytotoxicity in PC12 cells by scutellarin. Life Sci. 2004;74(24):2959-73.

120. Qian L, Shen M, Tang H, Tang Y, Zhang L, Fu Y, et al. Synthesis and protective effect of scutellarein on focal cerebral ischemia/reperfusion in rats. Molecules. 2012;17(9):10667-74.

121. Chen X, Cui L, Duan X, Ma B, Zhong D. Pharmacokinetics and metabolism of the flavonoid scutellarin in humans after a single oral administration. Drug Metab Dispos. 2006;34(8):1345-52.

122. Mao F, Li J, Wei H, Huang L, Li X. Tacrine-propargylamine derivatives with improved acetylcholinesterase inhibitory activity and lower hepatotoxicity as a potential lead compound for the treatment of Alzheimers disease. J Enzyme Inhib Med Chem. 2015;30(6):995-1001.

123. Girek M, Szymański P. Tacrine hybrids as multi-target-directed ligands in Alzheimer's disease: Influence of chemical structures on biological activities. Chem Pap. 2019;73(2):269-89.

124. Abcam. MTT Cell Proliferation Assay Kit Protocol. Biovision. 2018;211091(3):56.

125. Batta A. Comparative Study of Transaminase Ratio, AST, ALT and GGT in Cases of Chronic Hepatitis. Int J Med Heal Res. 2019;5(1):31-5.

126. Baarsma HA, Königshoff M, Gosens R. The WNT signaling pathway from ligand secretion to gene transcription: Molecular mechanisms and pharmacological targets. Pharmacol Ther. 2013;138(1):66-83.

127. Chen X, Zenger K, Lupp A, Kling B, Heilmann J, Fleck C, et al. Tacrine-Silibinin Codrug Shows Neuro and Hepatoprotective Effects in vitro and Pro-Cognitive and Hepatoprotective Effects in vivo. J Med Chem. 2012;55(11):5231-45.

128. Xie SS, Lan JS, Wang XB, Jiang N, Dong G, Li ZR, et al. Multifunctional tacrine-trolox hybrids for the treatment of Alzheimer's disease with cholinergic, antioxidant, neuroprotective and hepatoprotective properties. Eur J Med Chem. 2015;93:42-50. Available from: http://dx.doi.org/10.1016/j. ejmech.2015.01.058

129. Zhu J, Yang H, Chen $\mathrm{Y}$, Lin H, Li Q, Mo J, et al. Synthesis, pharmacology and molecular docking on multifunctional tacrine-ferulic acid hybrids as cholinesterase inhibitors against Alzheimer's disease. J Enzyme Inhib Med Chem. 2018;33(1):496-506.

130. Li SY, Jiang N, Xie SS, Wang KDG, Wang XB, Kong LY. Design, synthesis and evaluation of novel tacrine-rhein hybrids as multifunctional agents for the treatment of Alzheimer's disease. Org Biomol Chem. 2014;12(5):801-14.

131. Yang LX, Huang KX, Li HB, Gong JX, Wang F, Feng YB, et al. Design, synthesis and examination of neuron protective properties of alkenylated and amidated dehydro-silybin derivatives. J Med Chem. 2009;52(23):7732-52.

132. Gažák R, Svobodová A, Psotová J, Sedmera P, Přikrylová V, Walterová D, et al. Oxidised derivatives of silybin and their antiradical and antioxidant activity. Bioorganic Med Chem. 2004;12(21):5677-87.

133. Nencini C, Giorgi G, Micheli L. Protective effect of silymarin on oxidative stress in rat brain. Phytomedicine. 2007;14(2-3):129-35.

134. Loguercio C, Festi D. Silybin and the liver: From basic research to clinical practice. World J Gastroenterol. 2011;17(18):2288-301.

135. Heilmann J, Çalis I, Kirmizibekmez H, Schühly W, Harput S, Sticher O. Radical scavenger activity of phenylethanoid glycosides in FMLP stimulated human polymorph nuclear leukocytes: Structure-activity relationships. Planta Med. 2000;66(8):746-8.

136. Fang L, Kraus B, Lehmann J, Heilmann J, Zhang Y, Decker M. Design and synthesis of tacrine-ferulic acid hybrids as multi-potent anti-Alzheimer drug candidates. Bioorganic Med Chem Lett. 2008;18(9):2905-9.

137. Yan JJ, Cho JY, Kim HS, Kim KL, Jung JS, Huh SO, et al. Protection against $\beta$-amyloid peptide toxicity in vivo with long-term administration of ferulic acid. Br J Pharmacol. 2001;133(1):89-96.

138. Zhao YL, DeZhou G, Yang HB, Wang JB, Shan LM, Li RS, et al. Rhein protects against acetaminophen-induced hepatic and renal toxicity. Food Chem Toxicol. 2011;49(8):1705-10. Available from: http://dx.doi.org/10.1016/j. fct.2011.04.011

139. Zhang $A$, Sun $H$, Wang $X$. Recent advances in natural products from plants for treatment of liver diseases. Eur J Med Chem. 2013;63:570-7. Available from: http://dx.doi.org/10.1016/j.ejmech.2012.12.062 


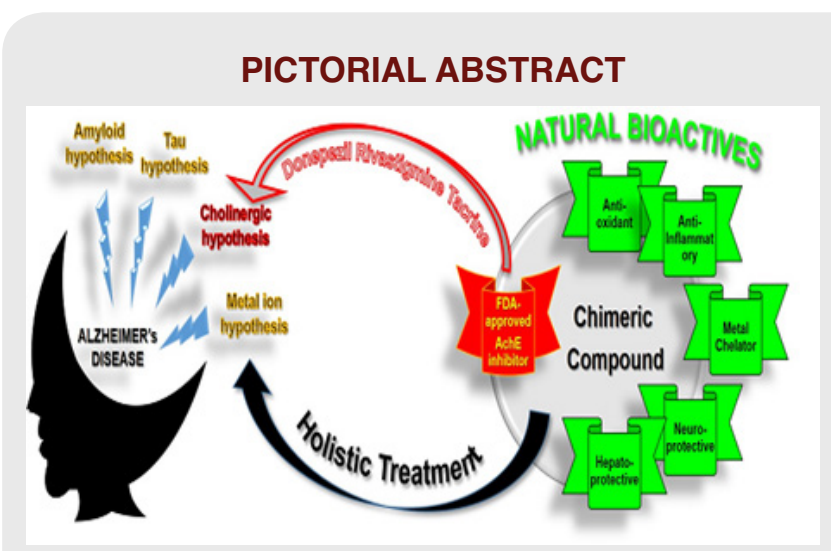

About Authors

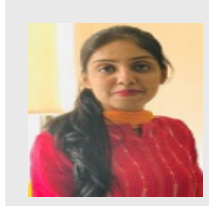

Ms. Illham Dhala, Department of Pharmaceutical Chemistry and Quality Assurance, SVKM's Dr. Bhanuben Nanavati College of Pharmacy, Mumbai, India.

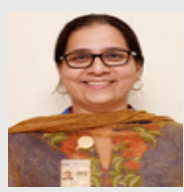

Dr. Tabassum Khan, Department of Pharmaceutical Chemistry and Quality Assurance, SVKM's Dr. Bhanuben Nanavati College of Pharmacy, Mumbai, India.

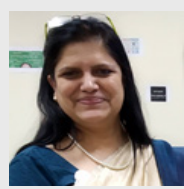

Dr. Arati Prabhu, Department of Pharmaceutical Chemistry and Quality Assurance, SVKM's Dr. Bhanuben Nanavati College of Pharmacy, Mumbai, India.

\section{SUMMARY}

- The current FDA-approved single mechanismtargeting anticholinesterase drugs developed for treatment of Alzheimer's disease (AD) have turned out to be palliative rather than curative.

- Many natural medicinal bioactives have the potential to overcome the unaddressed causal mechanisms contributing to AD.

- The first part of the review covers several natural product chimeras of the FDA-approved anticholinesterase inhibitors, donepezil and rivastigmine, developed as efficacious multifunctional anti-AD agents.

- The second part of the review focuses on development of tacrine based natural chimeras, designed with the intention of mitigating tacrineinduced hepatotoxicity.

Cite this article: Dhala I, Khan T, Prabhu A. Natural Chimeras of Existing Drugs for Alzheimer's Disease: Expanding the Target Landscape. Indian J of Pharmaceutical Education and Research. 2021;55(1s):s29-s47. 